\title{
Pre-flight Testing and Performance of a Ka-band Software Defined Radio
}

\author{
Joseph A. Downey ${ }^{1}$, Richard C. Reinhart ${ }^{2}$, and Thomas J. Kacpura ${ }^{3}$ \\ NASA Glenn Research Center, Cleveland, OH 44135
}

\begin{abstract}
National Aeronautics and Space Administration (NASA) has developed a space-qualified, reprogrammable, Ka-band Software Defined Radio (SDR) to be utilized as part of an onorbit, reconfigurable testbed. The testbed will operate on the truss of the International Space Station beginning in late 2012. Three unique SDRs comprise the testbed, and each radio is compliant to the Space Telecommunications Radio System (STRS) Architecture Standard. The testbed provides NASA, industry, other Government agencies, and academic partners the opportunity to develop communications, navigation, and networking applications in the laboratory and space environment, while at the same time advancing SDR technology, reducing risk, and enabling future mission capability. Designed and built by Harris Corporation, the Ka-band SDR is NASA's first space-qualified Ka-band SDR transceiver. The Harris SDR will also mark the first NASA user of the Ka-band capabilities of the Tracking Data and Relay Satellite System (TDRSS) for on-orbit operations. This paper describes the testbed's Ka-band System, including the SDR, travelling wave tube amplifier (TWTA), and antenna system. The reconfigurable aspects of the system enabled by SDR technology are discussed and the Ka-band system performance is presented as measured during extensive pre-flight testing.
\end{abstract}

\section{Introduction}

$\mathrm{T}$ HE Space Communications and Navigation (SCaN) Testbed Project is studying the development, testing, and operation of software defined radios (SDRs) and their associated applications for future use by NASA missions. SDR technology provides the ability to remotely change the functionality of a radio throughout the life of the mission. This capability allows the SDR to adapt to a number of external factors, such as evolving requirements, or an unpredictable environment. Additionally, the radio could be upgraded to improve interoperability with future missions, or to enhance performance. For example, a SDR could be reprogrammed to use a new modulation or encoding scheme to improve system throughput. To further advance SDR technology, NASA's Glenn Research Center has assembled a flight testbed which consists of reconfigurable and reprogrammable SDRs operating at Lband, S-band, and Ka-band, along with the required RF/antenna systems necessary for communications. The testbed, known as SCaN Testbed, will operate on a truss of the International Space Station (ISS) and provides the opportunity to study SDR technology in the space environment.

A significant accomplishment for the $\mathrm{SCaN}$ Testbed Project was the development of NASA's first spacequalified Ka-band transceiver. NASA developed the specifications and partnered with Harris Corporation to design and build the Ka-band SDR. The Ka-band SDR leverages Harris's experience with space-based digital processing platforms and terrestrial-based SDR technology. Adding an Operating Environment compliant to the NASA Space Telecommunications Radio System (STRS) Architecture Standard ${ }^{2}$ was a key factor in lowering the overall footprint and complexity of the radio software, as compared to the terrestrial SDR architecture standards. The resulting product is a highly-capable, state-of-the-art, reprogrammable Ka-band transceiver that is capable of data rates greater than $100 \mathrm{Mbps}$.

The SCaN Testbed and the Harris SDR will be the first NASA user of the Ka-band capabilities of the TDRSS for on-orbit operations. Other Ka-band NASA missions were in geostationary orbit, lunar orbit, or deep space, and utilized dedicated ground stations that were part of NASA's Near Earth Network (NEN) or Deep Space Network (DSN). Non-NASA entities such as the Japanese space agency's Advanced Land Observing Satellite (ALOS) have

\footnotetext{
${ }^{1}$ Computer Engineer, MS 54-1, AIAA Non-member.

${ }^{2} \mathrm{SCaN}$ Testbed Principal Investigator, MS 54-1, AIAA Non-member

${ }^{3}$ SCaN Testbed Communications System Lead, MS 142-2, AIAA Non-member.
}

1

American Institute of Aeronautics and Astronautics 
partnered with NASA to use TDRSS Ka-band for returning science data from low earth orbit. However, as more earth-science satellites are launched in the coming years, it is anticipated that the high data rates available at Kaband through TDRSS and the NEN will provide the bandwidth necessary to satisfy the daily science data downlink requirements ${ }^{2}$. The Harris SDR is applicable for these future earth science missions.

This paper focuses on the functionality and performance of the Harris SDR and the associated RF subsystem. As with most complex systems, each of the components were designed and tested stand-alone by their manufacturers. All of the components were then installed into the SCaN Testbed and the overall system was systematically tested and analyzed over the range of intended operating conditions. These tests were performed in order to verify that the $\mathrm{SCaN}$ Testbed was suitable for the space environment and that the integrated Ka-band system was performing as expected. Extensive testing has demonstrated that the Ka-band system meets all requirements and is suitable for onorbit operations.

The paper is organized as follows: Section II describes the SCaN Testbed Ka-band system, followed by a more indepth description of the Harris SDR hardware and software in Sections III and IV. Section V contains a description of the system level tests, and the performance highlights are summarized in Section VI. A high-level comparison to other Ka-band space-qualified modulators is contained in Section VII. Finally, proposed future experiments and the overall conclusions are shared in Sections VIII and IX.

\section{SCaN Testbed Ka-band System}

The Harris SDR communicates with the TDRSS over a full-duplex Ka-band link. The link is intended for user data, and is not currently capable of sending commands or receiving telemetry to/from SCaN Testbed. The key RF components that enable communication over this link are a travelling wave tube amplifier (TWTA), a high gain antenna, and an integrated gimbal assembly, as shown in Figure 1. The state-of-the-art, compact, lightweight TWTA was built by L3 Communications Electron Technologies Inc., and has a minimum output power of $40 \mathrm{~W}$ over the characterized frequency range of 25.5 to $25.8 \mathrm{GHz}^{2}$. The high gain antenna is a focal-fed parabolic reflector, with a dish diameter of 0.5 meter. The peak antenna gain is $39 \mathrm{~dB}$ for the $22 \mathrm{GHz}$ receive band, and $39.6 \mathrm{~dB}$ for the 25 $\mathrm{GHz}$ transmit band. The integrated gimbal assembly includes waveguide rotary joints, a 2-axis gimbaled pedestal, and associated control electronics.

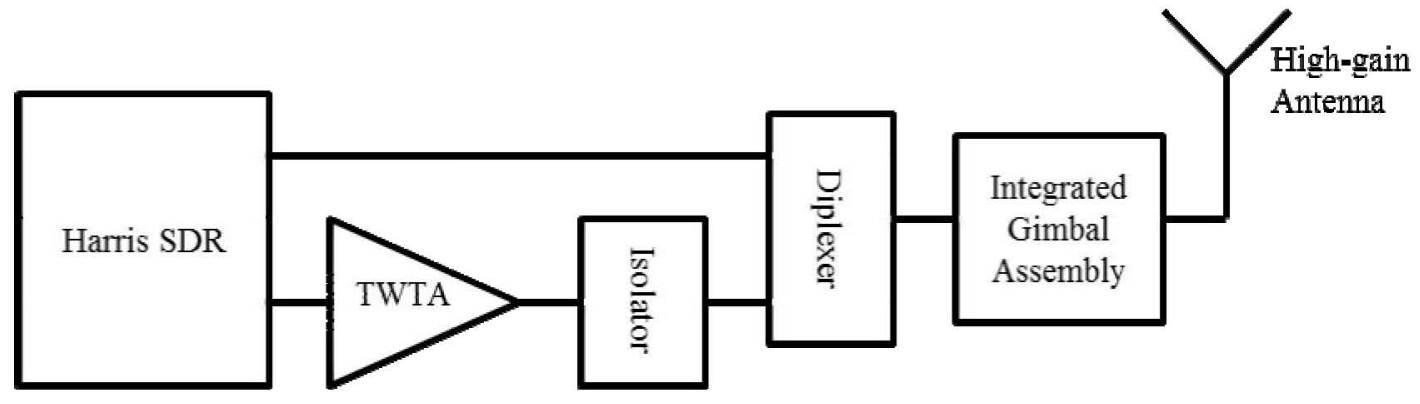

Figure 1: Ka-band System Components

The Harris SDR transmits a Ka-band exciter signal, on the order of a milliwatt, to drive the TWTA. The input drive level to the TWTA was chosen to 1) maximize output power, 2) account for component variations over temperature, and 3) minimize digital back-off required for higher-order modulation schemes. The optimized value is approximately $1 \mathrm{~dB}$ into saturation at ambient conditions.

Controlled by an antenna pointing algorithm running on the SCaN Testbed Avionics flight computer, the gimbaled antenna is able to function in closed-loop or open-loop operation. While operating in closed-loop, the antenna pointing system relies on a feedback measurement of the relative received power from the Harris SDR receiver. This relative power measurement is called the Antenna Pointing Quality Metric (APQM). The algorithm is designed for a measurement update rate of $10 \mathrm{~Hz}$ and has a dynamic range of $100 \mathrm{~dB}$. The algorithm provides a linear estimate of the received power in the entire dynamic range and does not require the receiver to be locked on the received signal. The APQM calculation is performed digitally within the modem. In open-loop tracking, the antenna follows a predetermined path. It is not anticipated to operate the Ka-band link with open-loop tracking due to excessive pointing error losses.

The SCaN Testbed Avionics unit provides power, commanding, and handles telemetry for the Ka-band system, as well as the S-band radios (not shown). The function of the Avionics flight computer is analogous to a spacecraft command and data handler (C\&DH). The Avionics receives commands from the ground via an ISS interface, 
interprets them, and then commands the payload accordingly. The Avionics is also responsible for monitoring the health and status of the components via temperature and current sensors. Telemetry is sent back to ground through the Avionics and the ISS interface. Additionally, the Avionics contains flash storage for handling large file transfers, and is reprogrammable to support future experiment objectives, such as networking between multiple SDRs.

\section{Harris SDR Hardware}

The Harris SDR is a multi-slice subsystem integrated into a chassis within the SCaN Testbed flight enclosure. The SDR consists of an AITech s950 single board computer, in-house designed modem board, digital IO board, sampler card, transmit RF, receive RF, master reference oscillator board, and two power supply boards. All of the circuit boards are interconnected through a $6 \mathrm{U}$ compact Peripheral Component Interconnect (cPCI) backplane. The main chassis output is at S-band and uses an external RF converter, built by Harris, to up-convert and down-convert to the Ka-band. The integrated system operates at a nominal transmit center frequency of 25.65 $\mathrm{GHz}$ and a nominal receive center frequency of 22.6795 GHz. These frequencies are in the band allocated to NASA for TDRSS operations. The flight unit main chassis is pictured in Figure 2. Figure 3 illustrates the

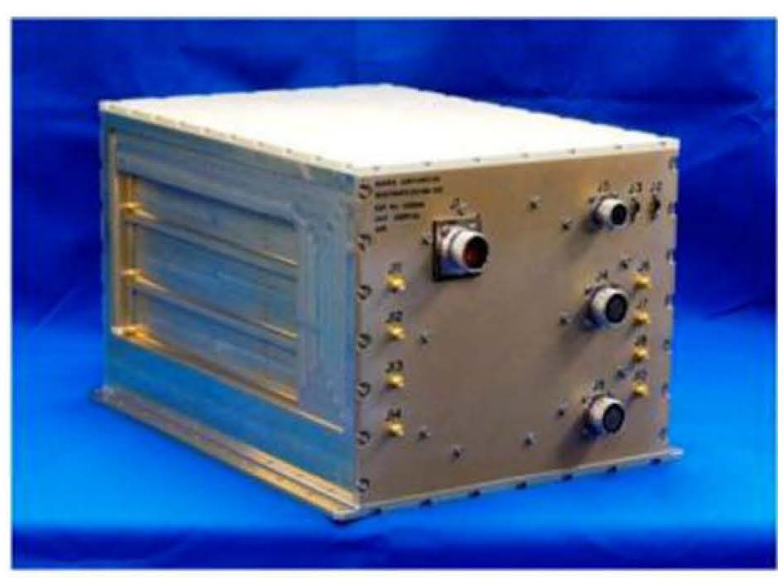

Figure 2: Harris SDR Chassis different functions within the radio and the interfaces between circuit boards, which are described below.

\section{Single Board Computer}

The single board computer (SBC) provides the overall control and monitoring of the SDR. The $3 \mathrm{U}$ cPCI board is radiation-tolerant, conduction-cooled, and has a PowerPC 750 class processor. The board has triple-redundant 128 MB SDRAM, 1MB boot and $64 \mathrm{MB}$ flash memory. The SBC runs the VxWorks operating system, loads programs from its memory into the processor, and executes the programs. It also stores application bit-streams and loads them into the modem card, when commanded. The computer board implements the clock function and maintains synchronization with the Avionics flight computer.

The Power PC processor on the single board computer runs an Operating Environment (OE). This includes an operating system and infrastructure service to applications and waveforms in accordance with the Space Telecommunications Radio System Standard (STRS). The OE middleware (compliant with the STRS Architecture Standard $^{3}$ abstracts the SDR hardware from the waveform application software. In addition to the OE, the SDR runs waveform applications, also compliant to STRS, which implement the unique capabilities of the radio to receive and transmit radio frequency (RF) signals.

\section{Digital I/O Board}

The digital input/output (I/O) card provides the external interfaces for communication between the SCaN Testbed Avionics processor and the Harris SDR. Commands from the Avionics processor are sent to the Harris single board computer through the digital I/O SpaceWire Router. The single board computer returns telemetry when polled, averaging once per second. The digital I/O card exchanges data between the Avionics processor and the modem card via a second SpaceWire interface that is capable of $100 \mathrm{Mbps}$, bidirectional. The I/O card also provides a discrete reset and power-enable signal for the modem card and RF subsystems.

The single board computer uses the digital I/O card to communicate with the modem through a $\mathrm{CPCI} / \mathrm{SpaceWire}$ interface using the Remote Memory Addressing Protocol (RMAP). This interface is used to load waveform applications from flash memory to the modem card, control waveform applications, and retrieve status on the operation of the waveform application and modem board services.

\section{V4 Space Programmable Modem}

The V4 Space Programmable Modem is a custom circuit board developed by Harris Corporation and is the core of the reconfigurable SDR. It provides the main signal processing hardware for the radio. The modem card consists of a switch/controller ASIC, four Xilinx IV radiation-tolerant FPGAs, a digital signal processor (DSP), and 256 Mbytes SDRAM with error detection and correction (EDAC). The SDRAM memory can accommodate up to four 
applications for each of the four FPGAs. The remaining memory is available for the DSP. There are two FPGAs wired to the transmit section of the radio and two FPGAs wired to the receive side. For additional flexibility, the neighboring FPGAs are also interconnected. The controller ASIC includes the scrubbing functions and internal SpaceWire Router to move data throughout the modem card. Digital clock manager blocks are supported within each FPGA.

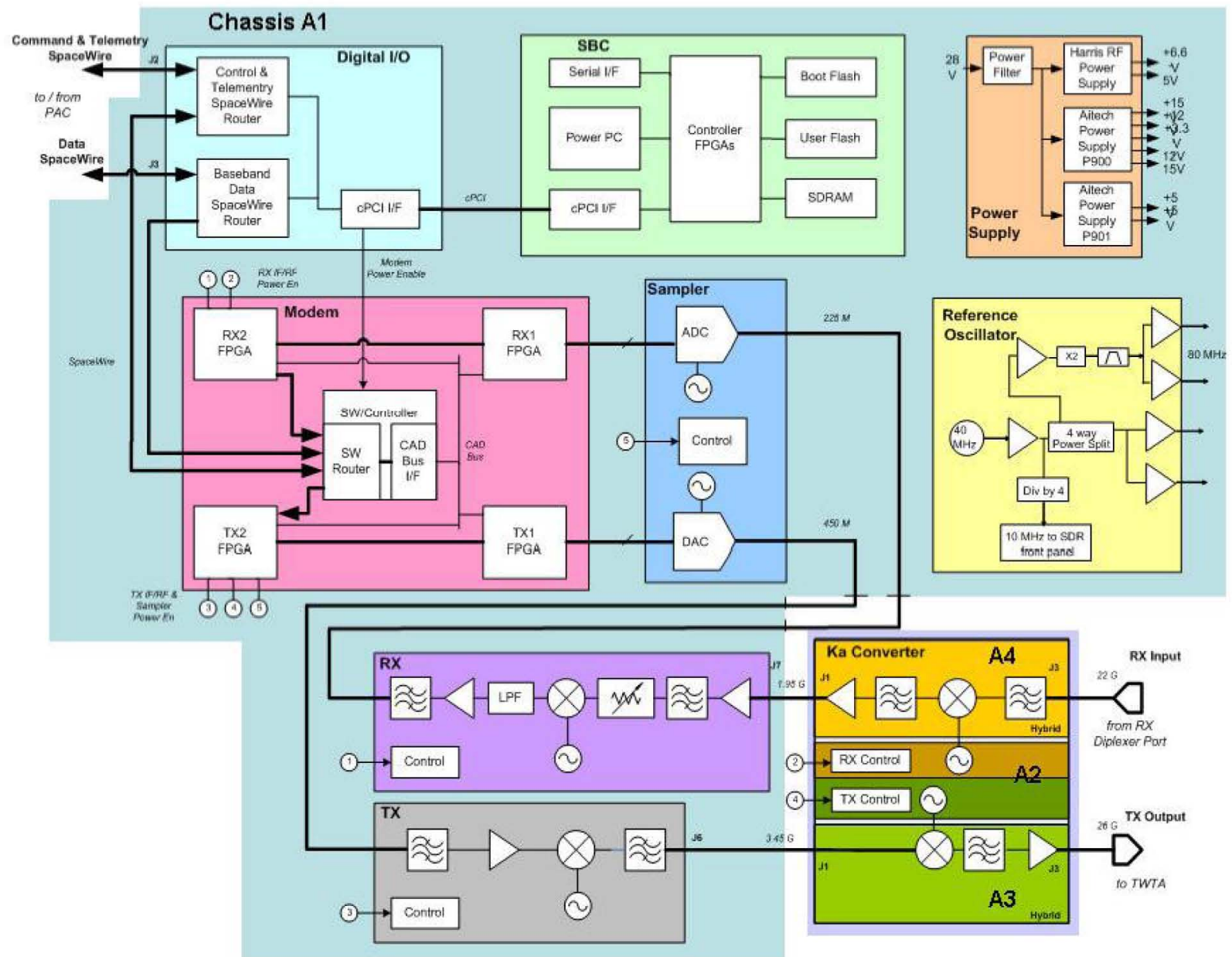

Figure 3: Harris Functional Components

The modem has direct interfaces and control over components in the RF modules. Key components include the programmable Integer- $\mathrm{N}$ and Fractional-N frequency synthesizers within the RF modules and the external Ka-band converter. These programmable synthesizers enable the RF transmit and receive center frequencies to be adjusted during operations. A step attenuator in the automatic gain control loop is also controlled by the V4 Space Modem. The V4 Space Modem has direct interface to the power enable signal of several modules within the RF transmit chain. This allows the transmitter and receiver to be operated independently, which can save power for simplex operations.

\section{Sampler Card / RF Modules / Ka-Converter}

The Sampler card performs the data conversion between the digital and analog domains. It contains the analog to digital converter $(\mathrm{ADC})$ for the receiver and the digital to analog converter (DAC) for the transmitter. The analog side of the Sampler card interfaces with the Receive and Transmit cards within the main chassis which convert the signals to S-band. The conversion from S-band to Ka-band occurs in the external Ka-band converter. Having the Kaband converter external allows it to be physically located closer to the RF subsystem, which is desired to minimize coaxial cable losses.

\section{Reference Oscillator}


The reference oscillator board provides the master clock for the Sampler card, RF Modules, and the KaConverter. The board uses a high-precision ovenized crystal oscillator (OXCO) as the base reference.

\section{Harris SDR Software}

\section{Boot-up}

The SDR runs an extensive built-in-test sequence during boot-up to verify that the hardware is operating nominally before loading any application software. First the single board computer runs a suite of self-tests, which includes testing the watchdog timer, flash memory, SDRAM, and other processor functions. Then the VxWorks real-time operating system is loaded. During this process the V4 Space Programmable Modem is momentarily powered on and a memory test is conducted on the modem's SDRAM. Finally, the STRS Operating Environment is loaded. The radio is now in stand-by mode, ready to accept commands. Due to the number of tests and size of the memory, the full platform built-in test takes up 4 minutes of the 5 minute boot time. The number of tests run can be reduced, if desired, for a faster boot time.

\section{STRS Operating Environment}

Harris Corporation developed an STRS-compliant Operating Environment (OE) during the program which processes commands, interacts with hardware through an abstraction layer, and configures the SDR. The hardware abstraction layer between the user's application software and the underlying hardware promotes reuse and portability by providing a well-defined interface.

A key requirement of STRS compliance is supplying sufficient documentation to enable future waveform development by third parties. Documentation delivered with the radio platform included a Hardware Interface Description (HID) document, an Interface Control Document, and an FPGA waveform application Wrapper's Guide. The HID document provides a description of the hardware resources available to a waveform developer. The FPGA wrapper provides template files for future FPGA designs and provides sample interfaces. The sample interfaces abstract the SpaceWire, backplane, and internal bus protocols. Also included are standard naming conventions for the FPGA code, and prototype files to aid simulation of the FPGAs. These documents will aid future waveform developers in creating new waveforms and porting existing waveforms to the Harris SDR.

\section{Waveform Applications}

After the STRS OE is loaded, the SDR can be commanded to load a waveform application from local memory. The files in memory include the FPGA bit-streams, DSP application, PowerPC application, and any configuration files. Together all of these files constitute a waveform application - however, any given waveform is not required to use all of the hardware resources. The current version of the Harris STRS OE does not permit multiple waveforms to be running simultaneously, but multiple waveforms can be stored on the SDR's on-board flash memory. This minimizes the amount of time to switch between multiple waveform applications.

An STRS-compliant waveform application was developed alongside the platform by Harris Corporation and was delivered with the hardware. The Ka-band waveform application was implemented primarily on the V4 Space Modem's FPGAs, with a PowerPC application providing command and control. Less than half of the FPGA resources were required, and the DSP was not used. The waveform parameters are listed in Table 1. A key feature of the waveform application was the ability to internally generate a pseudorandom bit stream of $2^{23}-1$ length for transmit and detect and measure a bit error rate on the receive link. These functions of generating and receiving data proved invaluable during all phases of system testing.

Table 1: Baseline Harris Ka-band Waveform Parameters

\begin{tabular}{|l|l|l|}
\cline { 2 - 3 } \multicolumn{1}{c|}{} & \multicolumn{1}{c|}{ Transmit } & \multicolumn{1}{c|}{ Receive } \\
\hline Frequency & $25.65 \mathrm{GHz}$ & $22.6795036 \mathrm{GHz}$ \\
\hline Data Rate & Variable (300 kbps to 100 Mbps) & Variable (300 kbps to 25 Mbps) \\
\hline Modulation & Offset-QPSK or continuous wave & BPSK \\
\hline Line-code & \multicolumn{2}{|c|}{ NRZ-L,-M } \\
\hline Coding & $\begin{array}{l}\text { Stacked Convolutional, Rate } 1 / 2, \\
\text { k=7, or bypassed }\end{array}$ & $\begin{array}{l}\text { Convolutional, Rate } 1 / 2, \mathrm{k}=7, \\
\text { or bypassed }\end{array}$ \\
\hline Framing & \multicolumn{2}{|c|}{$\begin{array}{c}\text { CCSDS 732.0-B-2 } \\
260 \text { byte frames, including 4 byte attached synchronization marker }\end{array}$} \\
\hline
\end{tabular}

American Institute of Aeronautics and Astronautics 


\begin{tabular}{|l|l|}
\hline Randomization & CCSDS 131.0-B-2 \\
\hline
\end{tabular}

The documentation associated with the Ka-band waveform included a User's Guide, and a Waveform Interface Control Document to aid developers in porting the Ka-band waveform to other platforms or reusing portions of the waveform for future developments.

\section{Radiation Fault Tolerance}

Exposing digital electronics to radiation in the space environment can have adverse effects. Electronic components are carefully selected which are designed, screened, and tested to operate in a radiation environment. Total dose of radiation is not major concern for a low earth orbit mission. However, single event upsets (SEUs), which occur when high-energy particles change the state of a memory cell, are a concern. In reprogrammable FPGAs this can either change the functionality of the device, or induce errors in the data, depending on where the SEU occurs. The technology that enables state-of-the-art space-qualified SDRs (reprogrammable FPGAs) is more susceptible to SEUs than their non-reprogrammable counterparts, such as one-time programmable FPGAs and radiation-hardened ASICs. Fortunately, proven techniques exist to mitigate SEUs in reprogrammable FPGAs. Current approaches require mitigations with a combination of both hardware and software to be effective.

To ensure the integrity of the waveform applications loaded on the FPGAs, a scrubbing algorithm is used. Single event upsets can corrupt the configuration registers of a reprogrammable static-RAM (SRAM)-based FPGA, essentially changing the functionality of the design. To minimize the impact of these upsets, the configuration bits of the FPGA load are continuously compared to a copy stored in EDAC-protected memory (SDRAM). To protect the application itself (data registers), techniques such as triple-mode-redundancy (TMR) may be employed to add fault tolerance. The baseline Harris Ka-band waveform application uses TMR.

The Virtex IV Space Programmable Modem was tested for single event upsets (SEUs) at the Texas A\&M Cyclotron and Berkeley facilities. The unit was tested in a radiation environment equal to 10 times a typical solar flare rate. When compared to non-triple mode redundant (TMR) design without scrubbing, the ASIC scrubbing reduced errors over 150 to 1 . Next it was tested with a TMR-only design, which increased the number of errors by approximately $10 \%$. Finally, when tested with TMR and with scrubbing, the errors were reduced 2500 to 1 . The increased errors using the TMR alone design probably resulted from an increase in the size of the circuit. From the test data, scrubbing provided the largest protection against SEUs.

The single board computer is also susceptible to SEUs, and uses a combination of TMR on the user memory, and error correction and control algorithms for the flash memory. A watchdog timer ensures that the processor does not enter into an unrecoverable state. In the event that the SDR fails to boot two consecutive times due to the watchdog timer timeout, the SDR will automatically switch over to the secondary boot flash which contains the Factory Kernel image. Steps can then be taken to investigate the cause of the timeout and recover the primary flash memory image to restore normal operations. It is not anticipated to modify the Factory Kernel on-orbit.

\section{System Level Tests}

The Harris SDR was thoroughly tested by the vendor before it was delivered to Glenn Research Center. The testing included: digital and RF performance, random vibration, thermal and thermal vacuum, electromagnetic interference, and electromagnetic compatibility. These tests verified that the SDR met all requirements, was suitable for the space environment, and was ready to be integrated into the SCaN Testbed. A complete set of system level performance and environmental tests were conducted with the Harris SDR and all the other components integrated, to verify that the SCaN Testbed was suitable for the space environment, and that the integrated Ka-band system was characterized and performed as expected. Three system tests are described in this section: TDRSS Compatibility, electromagnetic interference/ compatibility (EMI/EMC) testing, and thermal vacuum testing (TVAC). The environmental ground tests are of key interest, since they extend the normal system tests conducted under ambient conditions to an environment representative of the extremes experienced on-orbit.

\section{TDRSS Compatibility}

Prior to launch, a series of tests was conducted to ensure that all of the SCAN Testbed subsystems and radios were working correctly and were fully compatible with the TDRSS Space Network (SN). The SN is a network of TDRSS communications satellites and ground stations used by NASA for space-to-space communications. Compatibility testing verified that the system could properly communicate with the TDRSS and the White Sands ground station. The NASA Goddard Space Flight Center (GSFC) conducted the compatibility tests in collaboration with the Glenn Research Center and the Compatibility Test Sets (CTS) Project. The CTS Project is developing the next generation TDRSS compatibility test equipment, and provided the Ka-band relay equipment. 
The first portion of Compatibility testing was local testing, which tests the performance of the radio against the Space Network User's Guide (SNUG) requirements for operation with TDRSS. The ground support equipment (GSE) consisted of a Cortex HDR XXL high data rate modem built by Zodiac Data Systems, Ka-band frequency converter, RF measurement devices, and the associated RF interface components. The Cortex HDR modem is compatible with TDRSS modulation and forward error correction schemes.

After local testing, relay testing was performed with scheduled live TDRS events to the White Sands Complex in New Mexico. The SDR low level RF signal was amplified with a TWTA and transmitted through an outdoor dish antenna which was pointed at a TDRS and configured to produce the equivalent effective radiated isotropic power (EIRP) as the SCaN Testbed would have on ISS in low earth orbit. The link was calibrated by measuring the signal to noise ratios with a continuous wave signal (modulation off) in both transmit and receive.

Compatibility testing was successful and demonstrated that the Harris SDR was compatible with TDRSS. The testing also measured link performance and margins, including the implementation losses in the system. This data was useful to complete analysis to validate the predicted over-the-air link performance. Results from Compatibility testing are incorporated into section VI, Performance Highlights.

\section{EMI / EMC}

A series of electromagnetic interference (EMI) and compatibility (EMC) tests were conducted according to MILSTD-461 to verify that the radio, when installed and operating in the SCAN testbed system, met all the proper emission and operational ISS requirements. The radio passed all the EMI tests, which are designed to measure the conducted and radiated emissions from the radio in the system.

The results of the electromagnetic compatibility portion of the EMC test were of key interest in understanding the performance of the SDR from a communications perspective. The goal was to verify that operation was not perturbed when exposed to RF emissions across a range of expected frequencies. For any frequencies where operation was either perturbed or degraded, the corresponding change in the bit-error-rate of the RF link was measured. The reason this was important was any impact in operation was characterized due to emissions, from perhaps an onboard unintentional radiator. Knowing how the radio would respond to these radiators would help discern the difference between radiators interfering with performance, versus nominal RF link performance through the TDRSS.

The radiated susceptibility of interest was conducted over frequencies from $1 \mathrm{GHz}$ to $26 \mathrm{GHz}$. Testing was performed with hat couplers installed over the antenna. The hat coupler was connected to a simulated TDRSS interface, and the injected signal between the TDRSS simulator and the Harris SDR was representative of the lowest expected signal power level for the SDR. Any susceptibilities were observed by watching the change in measured link errors over the external RF link to the receiver, or if the RF link was lost.

The EMC test does not verify operation at all frequencies, rather it is exposed to discrete frequencies, typically five frequencies per octave. These scanned test frequencies did not always align with the internal operating frequencies of the radio, so testing was repeated to radiate at these frequencies to verify operation. In Table 3 , the frequencies where operation was impacted or the RF link was lost are described.

Table 2: RS03 Exceedances

\begin{tabular}{|c|c|c|c|c|}
\hline $\begin{array}{c}\text { Susceptibility } \\
\text { Frequency } \\
\text { (MHz) }\end{array}$ & $\begin{array}{c}\text { Threshold } \\
\text { Susceptibility } \\
(\mathbf{V} / \mathbf{m})\end{array}$ & $\begin{array}{c}\text { Limit } \\
\text { Requirement } \\
(\mathbf{V} / \mathbf{m})\end{array}$ & $\begin{array}{c}\text { Hardware and } \\
\text { Symptom }\end{array}$ & $\begin{array}{c}\text { Frequency } \\
\text { Function }\end{array}$ \\
\hline 2364 & 17.5 & 60 & High BER & \\
\hline 2535 & $<1$ & 60 & High BER & \\
\hline 2560 & $<1$ & 60 & Burst of errors & \\
\hline 2595 & 17.5 & 60 & $\begin{array}{c}\text { High BER/ error } \\
\text { bursts/ loss of sync }\end{array}$ & $\begin{array}{c}\text { Receive LO } \\
\text { Frequency }\end{array}$ \\
\hline 2656 & 17.5 & 60 & High BER/ error bursts & \\
\hline 2718 & $<1$ & 60 & Link error & \\
\hline 2775 & $<5$ & 60 & High BER & $\begin{array}{c}\text { Transmit LO } \\
\text { Frequency }\end{array}$ \\
\hline 4534 & 12.5 & 60 & High BER/ error bursts & \\
\hline
\end{tabular}


The local oscillator (LO) sensitivity to high levels of RF interferers may explain most of the susceptibility issues. The nearby frequencies are conceivably within the respective oscillator tuning ranges and may be pulling the devices out of lock. However, not all of the results were easily explained. The $4534 \mathrm{MHz}$ frequency may be some kind of inter-modulation scenario, and much further testing or analysis is required.

The results of the system testing should be contrasted against the radio level testing. The radiated susceptibility evaluation at the box level was less rigorous. No RF link was up, and the SDR was only monitored for a major failure, such as a reboot or lock-up condition. A key lesson learned was that the more rigorous RF link monitoring approach identified these vulnerabilities, and by the time it was at the system level it was too late to make any changes. The requirements for the box level test should have specified the same approach as the system level tests, by monitoring RF link performance.

\section{Thermal Vacuum Testing}

Thermal vacuum testing was performed to understand the flight system performance over varying temperatures in a vacuum. In space, there is no convection cooling, so testing in a vacuum is required to simulate the increased heating effects. There are also varying thermal effects due to the orientation of the payload on the ISS and the orbit around the earth, and operations can see wide temperature extremes. While the vendors performed TVAC testing of the SDR and TWTA individually, testing the integrated flight system was required to fully understand the Ka-band system performance.

The performance of several components in the Ka-band system vary as a function of temperature, including the transmit output power, frequency stability, receiver noise figure, and the behavior of the automatic gain control and the antenna pointing quality measurement (APQM). Characterizing the temperature dependencies within the radio enables future waveform developers to have the insight on how to properly compensate for any variances. An engineering model of the Harris SDR is available for future waveform development; however, it is not rated for environmental testing.

Another outcome of thermal vacuum testing was the validation of the predicted TWTA drive level across temperature. A visible indication of TWTA drive level is the amount of spectral regrowth seen in the modulated spectrum side-lobes. Spectrum plots were captured over temperature, as shown in Figure 4. While the main lobe does not change, the spectrum side-lobes increased as the temperature decreased. This plot is representative of the spectrum plots captured for each launched waveform, and each of the data rates of operation.

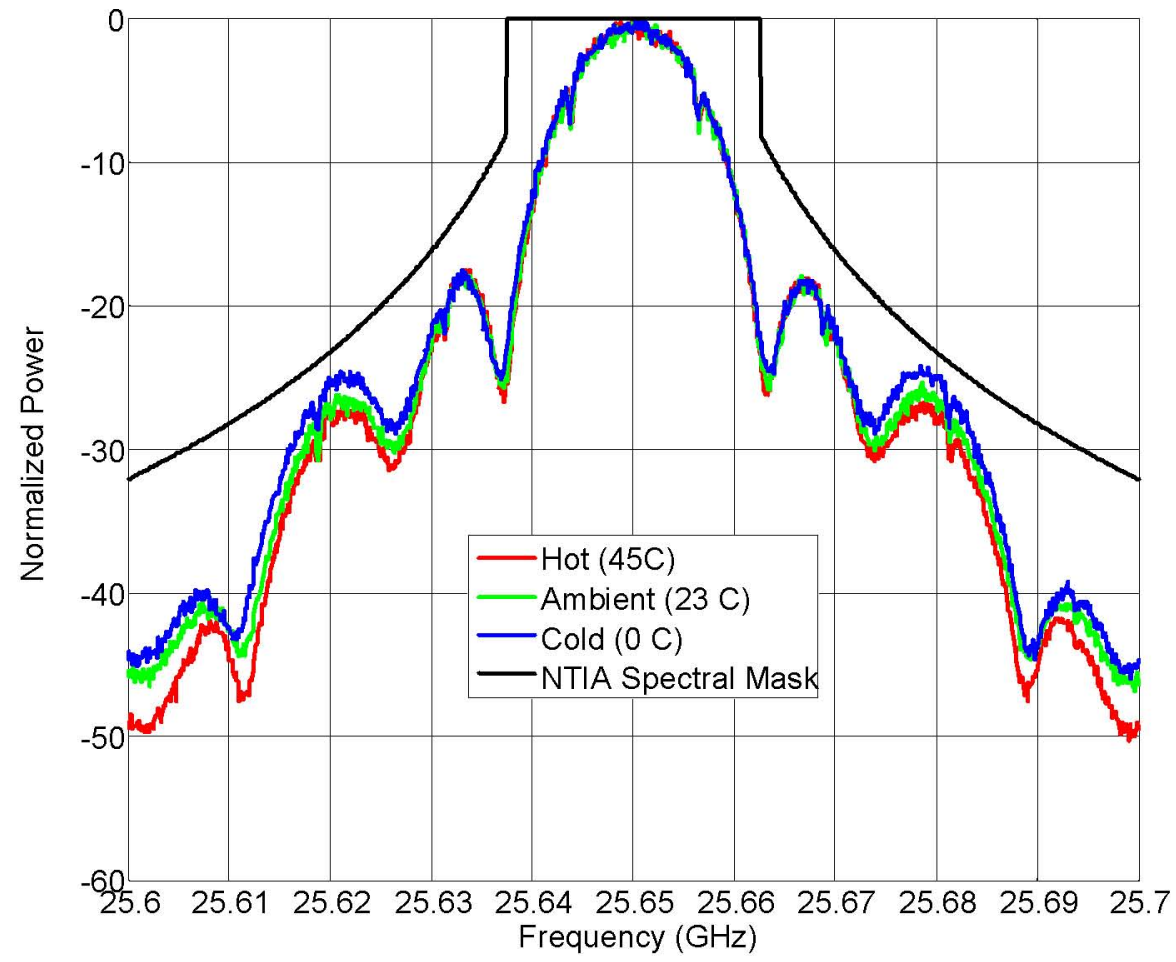

Figure 4: Spectrum for 12.5 Mbps, Coded

8

American Institute of Aeronautics and Astronautics 
The predicted TWTA input drive-level data is shown in Table 3. The results match the behavior observed in TVAC. The most spectral regrowth occurred at cold temperatures, where the TWTA was being driven $1.8 \mathrm{~dB}$ into saturation. The least spectral regrowth occurred at hot temperatures, where the input drive level was $1 \mathrm{~dB}$ before saturation. As expected, the drive level for ambient temperatures lies between the extremes.

Table 3: TWTA Drive Level Analysis

\begin{tabular}{|c|c|c|c|}
\hline $\begin{array}{c}\text { Temperature } \\
\left({ }^{\circ} \mathbf{C}\right)\end{array}$ & $\begin{array}{c}\text { Drive for Saturation } \\
(\mathbf{d B m})\end{array}$ & $\begin{array}{c}\text { Predicted Drive } \\
(\mathbf{d B m})\end{array}$ & $\begin{array}{c}\text { Difference } \\
(\mathbf{d B})\end{array}$ \\
\hline 45 & -2.4 & -3.03 & -0.63 \\
\hline 23 & -2.46 & -1.65 & 0.81 \\
\hline 0 & -2.8 & -1 & 1.8 \\
\hline
\end{tabular}

\section{Performance Highlights}

The primary highlight of the Harris SDR is the overall performance. The ample amount of signal processing available on the V4 Space Modem allows a high degree of performance for both the transmitter and receiver. The transmitter in-phase and quadrature-phase (IQ) waveform processing is performed digitally, yielding excellent modulation quality. The transmitter has a very clean spectrum and meets the National Telecommunications Information Association (NTIA) spectral mask requirements. The receiver has a low implementation loss and exceeds most of the required specifications to operate with TDRSS. The reference oscillator provides exceptional phase noise and frequency stability for both the transmitter and receiver.

A unique feature of software defined radios is the separation between the platform performance (limited by hardware), and the waveform performance (limited by the implementation). The combined performance can be measured through system testing. The platform and waveform performance highlights for the Harris SDR transmitter and receiver are provided in Table 4 and Table 5 . These test results are the outcome of all of the system and environmental testing described in the previous section.

Table 4: Platform Performance Highlights

\begin{tabular}{|c|c|c|c|}
\hline & Parameter & Specification & Harris SDR \\
\hline \multirow{5}{*}{ 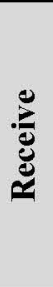 } & Frequency Band & $22.6795036 \mathrm{GHz}$ & $22.515-23.115 \mathrm{GHz}$ \\
\hline & Bandwidth & $50 \mathrm{MHz}$ & $129.6 \mathrm{MHz},-3 \mathrm{~dB}$ \\
\hline & Dynamic Range & -100 to $-50 \mathrm{dBm}$ & $\begin{array}{l}-100 \text { to }-30 \mathrm{dBm} \\
\text { up to } 2 \mathrm{dBm} \text { (no damage) }\end{array}$ \\
\hline & Noise Figure & $\begin{array}{l}3 \mathrm{~dB}(@, 25 \mathrm{C}) \\
4 \mathrm{~dB} \text { over }-30 \mathrm{C} \text { to }+60 \mathrm{C}\end{array}$ & $\begin{array}{l}2.3 \mathrm{~dB}(@ 25 \mathrm{C}) \\
2.9 \mathrm{~dB}(@ 60 \mathrm{C})\end{array}$ \\
\hline & Frequency Setability & $\pm 1 \mathrm{ppm}$ & $0.4 \mathrm{ppm}$ \\
\hline \multirow{7}{*}{ F } & Frequency Band & $25.65 \mathrm{GHz}$ & $25.65-26.16 \mathrm{GHz}$ \\
\hline & Bandwidth & $225 \mathrm{MHz}$ & $239 \mathrm{MHz},-3 \mathrm{~dB}$ \\
\hline & Frequency Setability & $\pm 1 \mathrm{ppm}$ & $0.43 \mathrm{ppm}$ \\
\hline & Frequency Stability & $\pm 1 \mathrm{ppm}$ over $-30 \mathrm{C}$ to $+60 \mathrm{C}$ & $0.02 \mathrm{ppm}$ \\
\hline & Long term stability & \pm 0.3 ppm over 24 hours, ambient & $0.012 \mathrm{ppm}$ \\
\hline & Spurious & $\begin{array}{l}\text { In-band, } 30 \mathrm{dBc} \\
\text { Out-of-band, } 60 \mathrm{dBc}\end{array}$ & $\begin{array}{l}\text { No in-band } 60 \mathrm{dBc} \\
\text { No out-of-band } 60 \mathrm{dBc}\end{array}$ \\
\hline & Phase Noise & $\begin{array}{l}1 \mathrm{~Hz}-10 \mathrm{~Hz} \leq 50^{\circ} \mathrm{rms} \\
10 \mathrm{~Hz}-100 \mathrm{~Hz} \leq 5.5^{\circ} \mathrm{rms} \\
100 \mathrm{~Hz}-1 \mathrm{kHz} \leq 2^{\circ} \mathrm{rms} \\
1 \mathrm{kHz}-150 \mathrm{MHz} \leq 2^{\circ} \mathrm{rms}\end{array}$ & $\begin{array}{l}4.1^{\circ} \mathrm{rms} \\
0.5^{\circ} \mathrm{rms} \\
0.5^{\circ} \mathrm{rms} \\
1.6^{\circ} \mathrm{rms}\end{array}$ \\
\hline
\end{tabular}


Table 5: Waveform Performance Highlights

\begin{tabular}{|c|c|c|c|}
\hline & Parameter & Specification & Harris SDR \\
\hline \multirow{6}{*}{$\frac{\mathscr{E}}{\mathscr{E}}$} & $\begin{array}{l}\text { Acquisition Threshold } \\
\text { (within } 5 \text { seconds) }\end{array}$ & $\mathrm{N} / \mathrm{A}$ & $\begin{array}{l}-107 \mathrm{dBm}(300 \mathrm{kbps}) \\
-91.2 \mathrm{dBm}(12.5 \mathrm{Mbps})\end{array}$ \\
\hline & Tracking Threshold & $\mathrm{N} / \mathrm{A}$ & $\begin{array}{l}-110.5 \mathrm{dBm}(300 \mathrm{kbps}) \\
-94.5 \mathrm{dBm}(12.5 \mathrm{Mbps})\end{array}$ \\
\hline & $\begin{array}{l}\text { Doppler Tracking Rate (center } \\
\text { Frequency }+/-15 \mathrm{kHz} \text { ) }\end{array}$ & $750 \mathrm{~Hz} /$ second & $1.2 \mathrm{MHz} /$ second \\
\hline & Acquisition Frequency Range & $+/-38 \mathrm{kHz}$ & $+/-45 \mathrm{kHz}$ \\
\hline & $\begin{array}{l}\text { Implementation Loss at } 10^{-5} \text { bit } \\
\text { error rate, uncoded }\end{array}$ & $2.4 \mathrm{~dB}$ & $\begin{array}{l}<0.3 \mathrm{~dB} @ 12.5 \mathrm{Mbps} \\
<0.75 \mathrm{~dB} @ 25 \mathrm{Mbps}\end{array}$ \\
\hline & $\begin{array}{l}\text { Implementation Loss at } 10^{-8} \text { bit } \\
\text { error rate, uncoded }\end{array}$ & $\mathrm{N} / \mathrm{A}$ & $\begin{array}{l}<0.5 \mathrm{~dB} @ 12.5 \mathrm{Mbps} \\
<1 \mathrm{~dB} \text { a } 25 \mathrm{Mbps}\end{array}$ \\
\hline \multirow{3}{*}{ 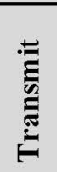 } & Carrier Suppression & $>30 \mathrm{~dB}$ & $>45 \mathrm{~dB}$ \\
\hline & Phase Imbalance & $\pm 3^{\circ}$ & $\pm 0.5^{\circ}$ \\
\hline & Gain Imbalance & $\pm 0.25 \mathrm{~dB}$ & $0.05 \mathrm{~dB}$ \\
\hline
\end{tabular}

Bit error rate curves from TDRSS Compatibility testing are shown in the figures below. The BER curves demonstrate the performance over a range of signal power conditions. Minor deviations are seen between the local and relay tests due to a combination of errors in the GSE calibration, the dynamics of a live TDRSS link, and measurement error. The curves show a very low implementation loss for the receiver, far exceeding the conservative specification requirement. The transmit BER curves demonstrate the Harris SDR coded performance at $100 \mathrm{Mbps}$ over varying signal conditions. Compatibility testing showed that the Harris SDR performed as expected, with margin, including the highest data rates for both transmit (100 Mbps) and receive (12.5 Mbps). These results validate the link budget assumptions and are indicative of the performance to expect on-orbit.

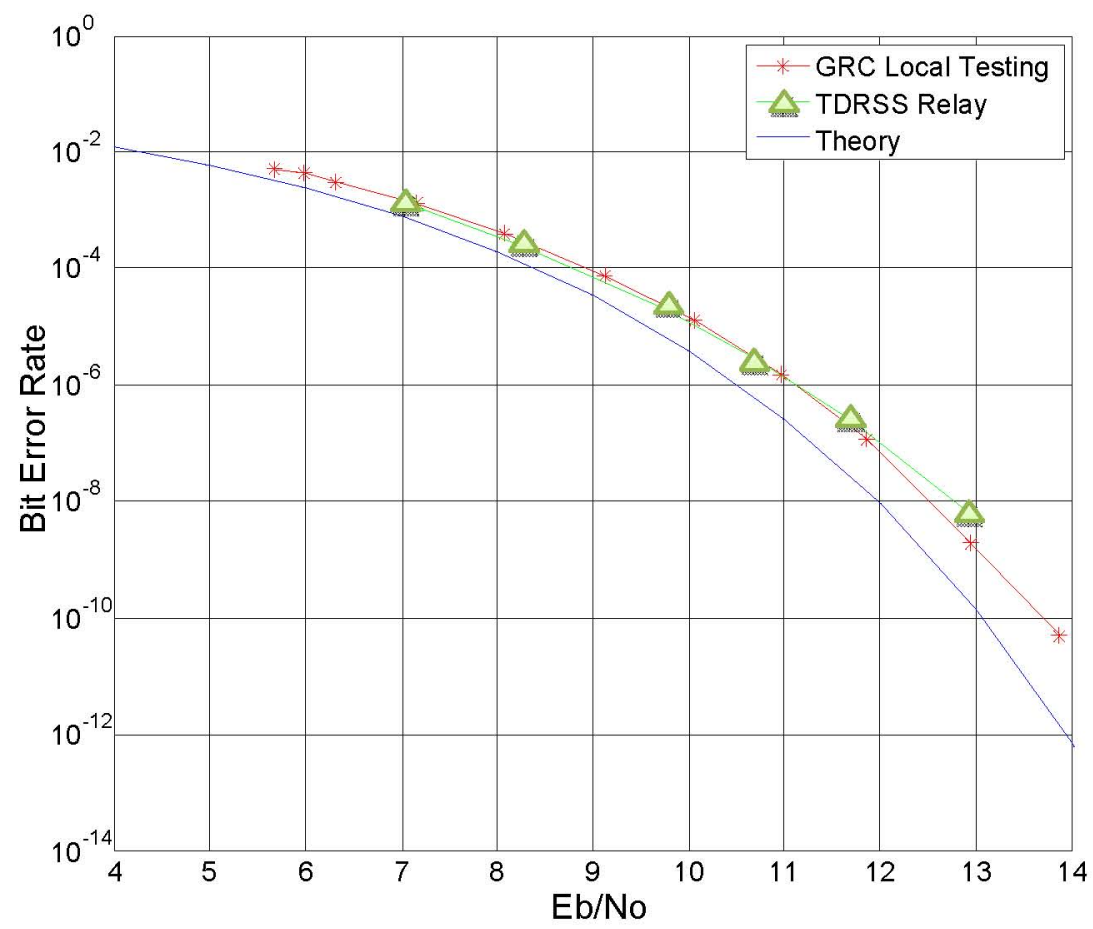

Figure 5: Receiver (Fow ard Link) Uncoded Performance, 12.5 Mbps 


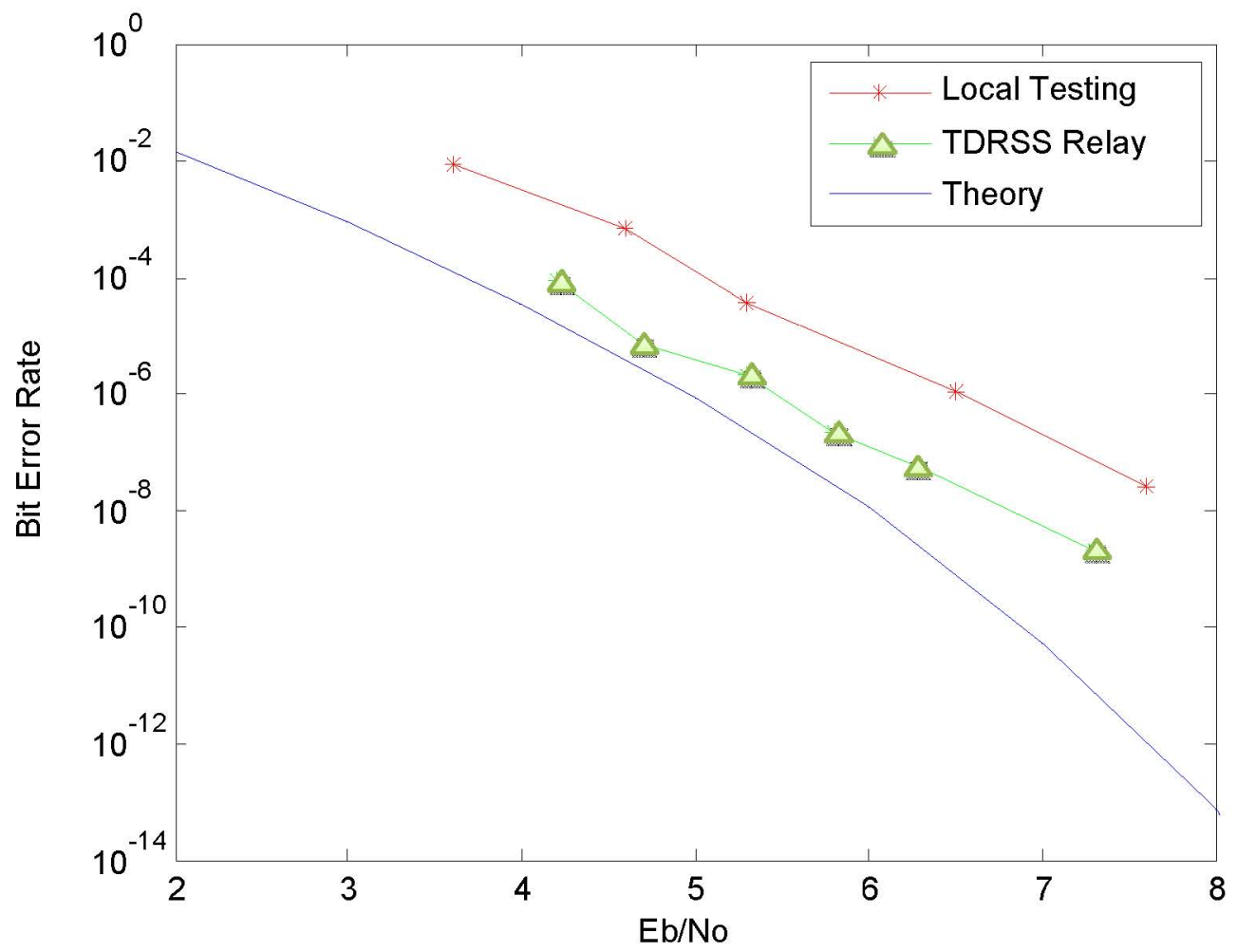

Figure 6: Transmitter (Return Link) Coded Performance, 100 Mbps

\section{Comparison to Space-qualified Ka-band Radios}

The Harris SDR is NASA's first space-qualified Ka-band transceiver. Other NASA missions, such as the Mars Reconnaissance Orbiter (MRO), Solar Dynamic Observatory (SDO), and Lunar Reconnaissance Orbiter (LRO) have utilized Ka-band communications; however, the Ka-band radios were transmit-only. In these cases, Ka-band was used for returning telemetry and science data to earth. These radios had reconfigurable parameters, but were not fully reprogrammable like the Harris SDR. Spacecraft with a Ka-band downlink use another frequency band for command and telemetry. Adding a space-qualified Ka-band receiver could simplify future mission architectures by having both transmit and receive capability, eliminating the need for multiple radios at different frequency bands. It also enables a high data rate uplink to the spacecraft over Ka-band.

A direct comparison of the capabilities and size weight and power ( $\mathrm{SWaP}$ ) of the Harris SDR to other spacequalified high-rate modems is difficult, since there are significant differences. As previously mentioned, the Harris SDR is NASA's first Ka-band transceiver, so the SWaP will understandably be higher than a space-qualified transmitter. Also, some mission architectures implement certain waveform function such as forward error correction and framing in the spacecraft command and data handler (C\&DH). The key features of the Harris SDR compared to space-qualified Ka-band transmitters are shown in Table 6.

Compared to the conventional modulators, it is quickly apparent that software defined radio technology enables a high degree of flexibility. Conventional modulators typically have conditions on supported data rates, forward error correction schemes, and frequency bands. There are options when the unit is purchased, but none can be changed after the hardware is delivered. The attraction of software defined radio is the flexibility, and ultimately reduced risk for a given mission to adapt to changing requirements or unknown conditions after launch. 
Table 6: Space-qualified Radio Comparison

\begin{tabular}{|c|c|c|c|c|c|c|c|}
\hline & \multirow{2}{*}{\begin{tabular}{l}
\multicolumn{1}{c}{ Harris SDR } \\
Reconfigurable \\
$25.65-26.16$ \\
$\mathrm{GHz}$
\end{tabular}} & \multirow{2}{*}{$\begin{array}{l}\begin{array}{c}\text { GSFC High- } \\
\text { Rate Modulator }\end{array} \\
\text { Fixed: } \\
25.5 \text { to } 27 \mathrm{GHz}\end{array}$} & \multicolumn{2}{|c|}{$\begin{array}{l}\text { General Dynamics } \\
\text { HRT-440 }{ }^{\dagger} \text { HRT150 }\end{array}$} & \multirow{2}{*}{$\begin{array}{c}\begin{array}{c}\text { Space Micro } \\
\boldsymbol{\mu} \boldsymbol{K} \boldsymbol{a} \boldsymbol{T} \boldsymbol{x}^{\S}\end{array} \\
20-30 \mathrm{GHz}\end{array}$} & \multirow{2}{*}{$\begin{array}{l}\begin{array}{c}\text { Small Deep } \\
\text { Space } \\
\text { Transponder }\end{array} \\
31.8 \text { to } 32.3 \\
\mathrm{GHz}\end{array}$} \\
\hline \multirow{6}{*}{ : } & Frequency & & & $\begin{array}{l}\text { Standard: } \\
\text { X-band } \\
\text { Option: } \\
\text { Ka-band }\end{array}$ & $\begin{array}{l}\text { Standard: } \\
\text { Ku-band } \\
\text { Option: } \\
\mathrm{X}, \mathrm{Ka}- \\
\text { band } \\
\end{array}$ & & \\
\hline & Data Rate & $\begin{array}{l}\text { Software } \\
\text { Defined } \\
>300 \mathrm{Mbps} \\
\text { with 8-PSK }\end{array}$ & $\begin{array}{l}\text { Reconfigurable: } \\
300 \text { Mbps max } \\
\text { with 8-PSK }\end{array}$ & $\begin{array}{l}\text { Fixed: } \\
\text { Dual data } \\
\text { rates, } 440 \\
\text { Mbps } \\
\max \\
\end{array}$ & $\begin{array}{l}\text { Fixed: } \\
150 \mathrm{Mbps}\end{array}$ & $\begin{array}{l}\text { Options: } \\
0.1 \text { to } 100 \mathrm{Mbps}, \\
0.1 \text { to } 1 \mathrm{Gbps}, \\
1 \text { to } 2.25 \mathrm{Gbps}, \\
3.2 \mathrm{Gbps}\end{array}$ & $\begin{array}{l}30 \text { Mbps } \max \\
\text { (QPSK) }\end{array}$ \\
\hline & Modulation & $\begin{array}{l}\text { Software } \\
\text { Defined }\end{array}$ & $\begin{array}{l}\text { Reconfigurable: } \\
\text { QPSK, OQPSK, } \\
\text { GMSK, 8-PSK } \\
\text { TCM, 8-PSK, } 16 \\
\text { QAM, 16-PSK, } \\
\text { 16-APSK }\end{array}$ & \multicolumn{2}{|l|}{$\begin{array}{l}\text { Fixed: } \\
\text { OQPSK }\end{array}$} & $\begin{array}{l}\text { Options: } \\
\text { BPSK, OQPSK, } \\
\text { 8-PSK, } 16 \text { QAM }\end{array}$ & $\begin{array}{l}\text { Reconfigurable: } \\
\text { Subcarrier, } \\
\text { BPSK, QPSK }\end{array}$ \\
\hline & Coding & $\begin{array}{l}\text { Software } \\
\text { Defined }\end{array}$ & None (C\&DH) & $\begin{array}{l}\text { Standard: } \\
\text { LDPC } \\
7 / 8 \\
\text { Options: } \\
\text { Reed- } \\
\text { Solomon, } \\
\text { Rate } 1 / 2 \\
\text { Conv. }\end{array}$ & $\begin{array}{l}\text { Standard: } \\
\text { Stacked } \\
\text { Viterbi } \\
\text { Options: } \\
\text { Reed- } \\
\text { Solomon, } \\
\text { LDPC } 7 / 8\end{array}$ & $\begin{array}{l}\text { Standard: } \\
\text { Convolutional } \\
\text { Options: } \\
\text { Reed-Solomon } \\
\text { \& BCH }\end{array}$ & $\begin{array}{l}\text { Convolutional, } \\
\mathrm{k}=7, \mathrm{k}=15\end{array}$ \\
\hline & Framing & $\begin{array}{l}\text { Software } \\
\text { Defined }\end{array}$ & None (C\&DH) & \multicolumn{2}{|c|}{ Yes, fixed } & None (C\&DH) & None (C\&DH) \\
\hline & Output Power & $3 \mathrm{~mW}$ & $2 \mathrm{~mW} \min$ & $10 \mathrm{~mW}$ & $2 \mathrm{~W}$ & $3 \mathrm{~mW}$ & $2.5 \mathrm{~mW}$ \\
\hline \multirow{5}{*}{ 芯 } & Frequency & $\begin{array}{l}\text { Reconfigurable } \\
22.5-23.1 \\
\mathrm{GHz}\end{array}$ & $\mathrm{N} / \mathrm{A}$ & \multicolumn{2}{|c|}{$\mathrm{N} / \mathrm{A}$} & $\mathrm{N} / \mathrm{A}$ & X-band \\
\hline & Data Rate & $\begin{array}{l}\text { Software } \\
\text { Defined }\end{array}$ & $\mathrm{N} / \mathrm{A}$ & \multicolumn{2}{|c|}{$\mathrm{N} / \mathrm{A}$} & $\mathrm{N} / \mathrm{A}$ & $\begin{array}{l}7.8125 \text { to } 4000 \\
\text { bps }\end{array}$ \\
\hline & Demodulation & $\begin{array}{l}\text { Software } \\
\text { Defined }\end{array}$ & $\mathrm{N} / \mathrm{A}$ & \multicolumn{2}{|c|}{$\mathrm{N} / \mathrm{A}$} & $\mathrm{N} / \mathrm{A}$ & PM/PSK, NRZ \\
\hline & Coding & $\begin{array}{l}\text { Software } \\
\text { Defined }\end{array}$ & $\mathrm{N} / \mathrm{A}$ & \multicolumn{2}{|c|}{$\mathrm{N} / \mathrm{A}$} & $\mathrm{N} / \mathrm{A}$ & None (C\&DH) \\
\hline & Framing & $\begin{array}{l}\text { Software } \\
\text { Defined }\end{array}$ & $\mathrm{N} / \mathrm{A}$ & \multicolumn{2}{|c|}{$\mathrm{N} / \mathrm{A}$} & $\mathrm{N} / \mathrm{A}$ & None $(\mathrm{C} \& D H)$ \\
\hline \multirow{3}{*}{$\frac{\hbar}{\sqrt[\pi]{n}}$} & $\begin{array}{l}\text { Dimensions } \\
(\mathbf{L}, \mathbf{W}, \mathbf{H})\end{array}$ & $\begin{array}{l}40.64 \mathrm{~cm} \mathrm{x} \\
31.75 \mathrm{~cm} \mathrm{x} \\
22.86 \mathrm{~cm} \\
\end{array}$ & $\begin{array}{l}<25 \mathrm{~cm} \mathrm{x} \\
<25 \mathrm{~cm} \mathrm{x} \\
<10 \mathrm{~cm}\end{array}$ & $\begin{array}{l}20.3 \mathrm{~cm} \mathrm{x} \\
16.8 \mathrm{~cm} \mathrm{x} \\
7.6 \mathrm{~cm} \\
\end{array}$ & $\begin{array}{l}20.3 \mathrm{~cm} \mathrm{x} \\
16.8 \mathrm{~cm} \mathrm{x} \\
8.1 \mathrm{~cm} \\
\end{array}$ & $\begin{array}{l}24.4 \mathrm{~cm} \mathrm{x} \\
21.7 \mathrm{~cm} \mathrm{x} \\
3.8 \mathrm{~cm} \\
\end{array}$ & $\begin{array}{l}15.5 \mathrm{~cm} \mathrm{x} \\
16.6 \mathrm{~cm} \mathrm{x} \\
11.4 \mathrm{~cm} \\
\end{array}$ \\
\hline & Mass & $19.2 \mathrm{~kg}$ & $<4 \mathrm{~kg}$ & $2.3 \mathrm{~kg}$ & $2.3 \mathrm{~kg}$ & $2.3 \mathrm{~kg}$ & $3.2 \mathrm{~kg}$ \\
\hline & DC Power & $100 \mathrm{~W}$ & $\leq 30 \mathrm{~W}$ & $15 \mathrm{~W}$ & $47 \mathrm{~W}$ & $50 \mathrm{~W}$ & $19.5 \mathrm{~W}$ \\
\hline
\end{tabular}

A comparison of the size, weight, and power of the Harris SDR compared to the conventional modulators is problematic. The inclusion of a high-rate receiver does add size, weight and power to the Harris SDR. Also, it is expected that reprogrammable SDR technology will impose a modest increase in power consumption for equivalent

\footnotetext{
*http://ipp.gsfc.nasa.gov/ft_tech_ka_band_mod_transl.shtm

${ }^{\dagger} \mathrm{http}: / / \mathrm{www} \cdot \mathrm{gd}$-ais.com/documents/HRT-440-DS5-910-1b.pdf

http://www.gd-ais.com/documents/HRT\%20150\%20-\%20DS5-111-12.pdf

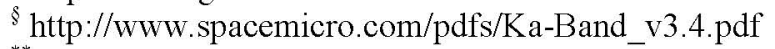

${ }^{* *}$ http://www.gd-ais.com/documents/SDST\%20DS5-111-10.pdf
} 
or greater capabilities. The gap in SWaP between the Harris SDR and the conventional modulators is larger than it could be due to a balance of schedule, mechanical, and thermal constraints encountered during the procurement of the Harris SDR and integration into the SCaN Testbed. Harris Corporation designed, built, and delivered a breadboard, engineering, and flight SDR in under 18 months, and made several design decisions to ensure a high probability of success and a timely delivery. One example is that a standard cPCI chassis adds a considerable amount of mass compared to a stacked $6 \mathrm{U}$ configuration. A mass requirement was not given to Harris to allow the greatest degree of freedom in meeting other constraints. Other size, weight, and power optimizations were possible, but not implemented due to schedule constraints. The Harris SDR is a first generation space-qualified Ka-band SDR, and $\mathrm{SWaP}$ improvements are anticipated for future missions.

\section{Future Experiment Use Planned}

In studying the development, testing, and operation of SDRs, a major component will be demonstrating enhanced waveform application capabilities after launch. Current experiment plans include the use of modern forward error correction codes, such as Low Density Parity Check (LDPC) codes, and Serial Concatenated Convolutional Codes (SCCC), and bandwidth efficient modulations such as GMSK and 8-PSK. A subset of these waveforms is aligned with the Space Network (SN) modernization and upgrade project. Other experiments have been proposed involving disruption tolerant networking (DTN), and adaptive modulation and encoding. In order to better understand the RF environment, a waveform which saves the received ADC samples to memory is also planned. The waveforms developed will be added to the STRS Repository for future use by NASA missions.

The SCaN Testbed Project is just beginning the experiments phase, and further work and proposals are anticipated. The system will be available for experimenters beginning in 2013.

\section{Conclusion}

The Harris SDR is NASA's first space-qualified Ka-band transceiver, and has successfully demonstrated a technology readiness level (TRL) of 6 , which is the last qualification before operation in the space environment. The radio has been integrated into NASA's SCaN Testbed, and has successfully completed system-level random vibration, EMI/EMC, TVAC and TDRSS compatibility testing. The primary highlight of the Harris SDR is the exceptional performance of the transmitter and receiver, enabled by a highly-capable RF front-end and digital signal processing. The demonstration of this Ka-band space-qualified radio validates the SDR platform for use in SCaN Testbed and future space missions.

The flexible nature of SDR technology has been presented. As an example of how SDR technology can be reused, Harris was recently awarded a contract for the Global Satellite-Based Aircraft Tracking Hosted Payload on the Iridium NEXT Constellation. This innovative payload will have a positive impact on the Global Aviation Community. The Hosted Payload concept/architecture is based upon the Ka-band SDR that was developed on the NASA/Harris cooperative agreement. Leveraging the SCaN Testbed Ka-band SDR was a key contributor to this award.

\section{References}

${ }^{1}$ Johnson, S. K., Reinhart, R. C., Kacpura, T. J., "CoNNeCT's Approach for the Development of Three Software Defined Radios for Space Application," Aerospace Conference 2012 IEEE, Big Sky, MT, March 2012.

${ }^{2}$ Reinhart, R., Kacpura, T., Handler, L., Hall, C., Mortensen, D., Johnson, S., et. al., "Space Telecommunications Radio System (STRS) Architecture Standard, Release 1.02.1" NASA/TM-2010-216809, NASA Glenn Research Center, Cleveland OH, December 2010 .

${ }^{3}$ McCarthy, K. P., Stocklin, F. J., Geldzahler, B.J., Friedman, D. E., Celeste, P. B., "NASA's Evolution to Ka-Band Space Communications for Near-Earth Spacecraft," SpaceOps 2010, AIAA, Goddard Space Flight Center, Greenbelt, MD, April 2010.

${ }^{4}$ Simons, R. N., Force, D. A., Spitsen, P. C., Menninger, W. L., Robbins, N. R., Dibb, D. R., Todd, P. C., "High Efficiency K-Band Space Travelling-Wave Tube Amplifier for Near-Earth High Data Rate Communications" NASA/TM-2010-216262, Glenn Research Center, Cleveland OH, March 2010. 

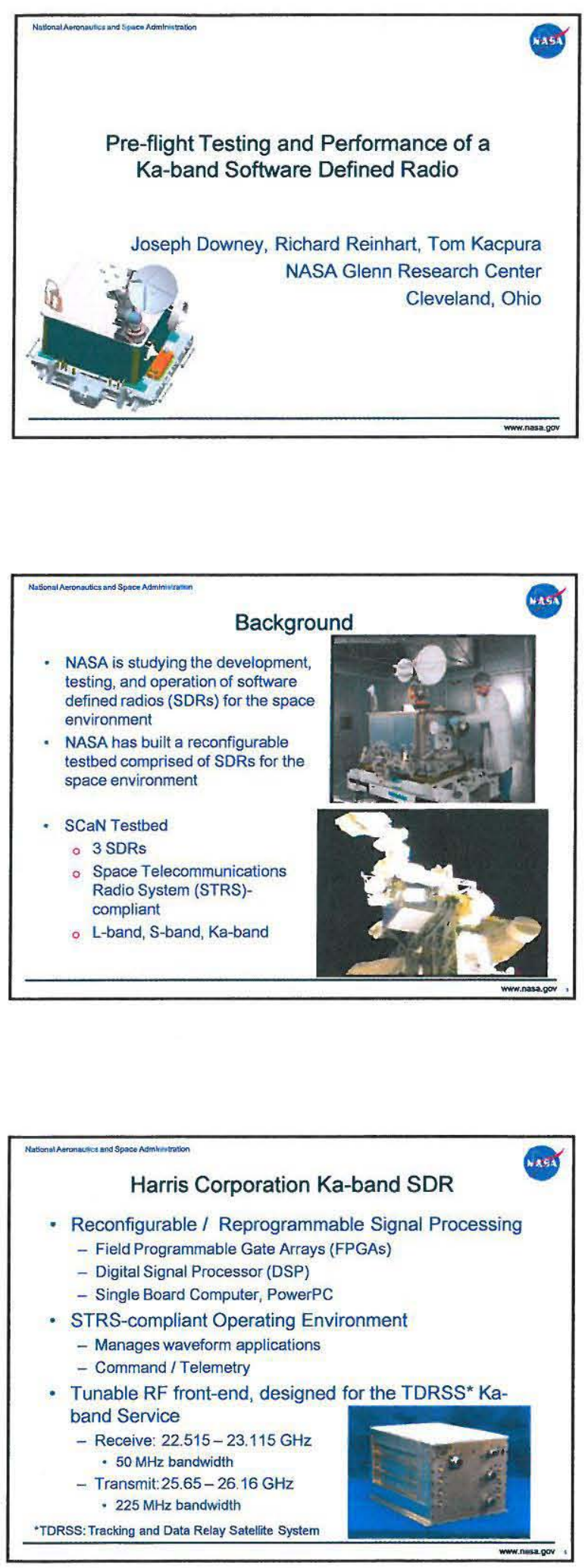
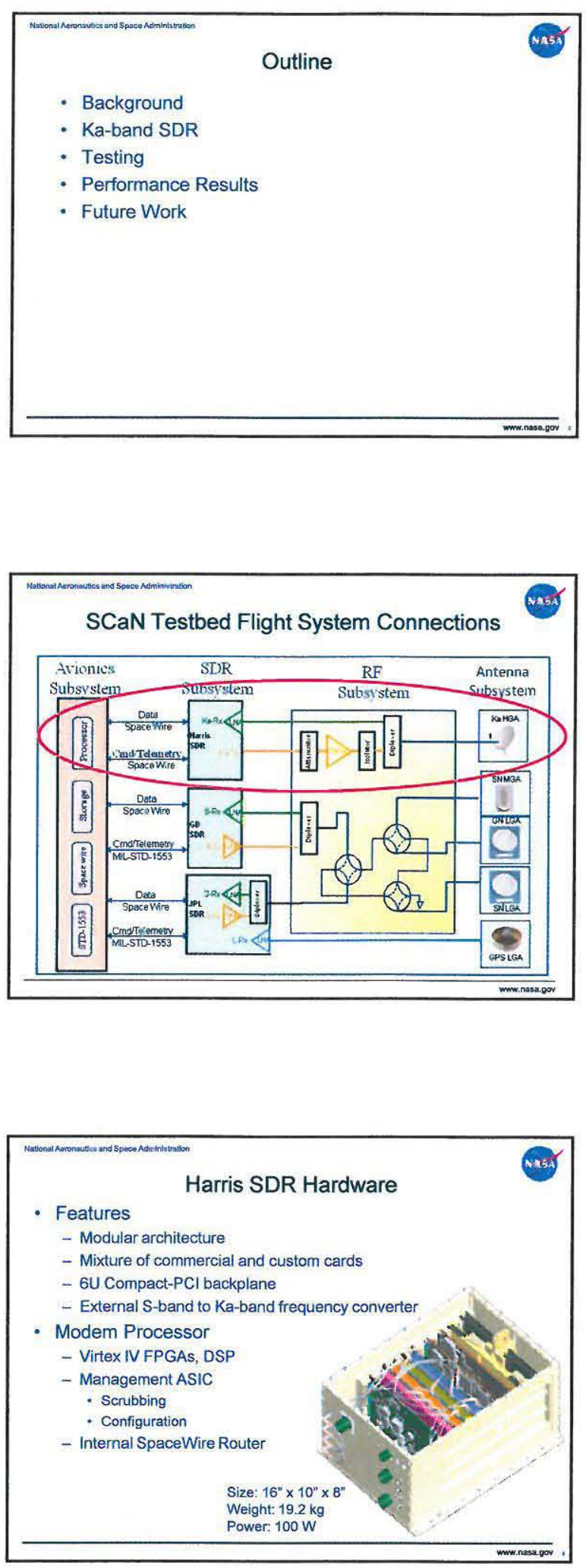

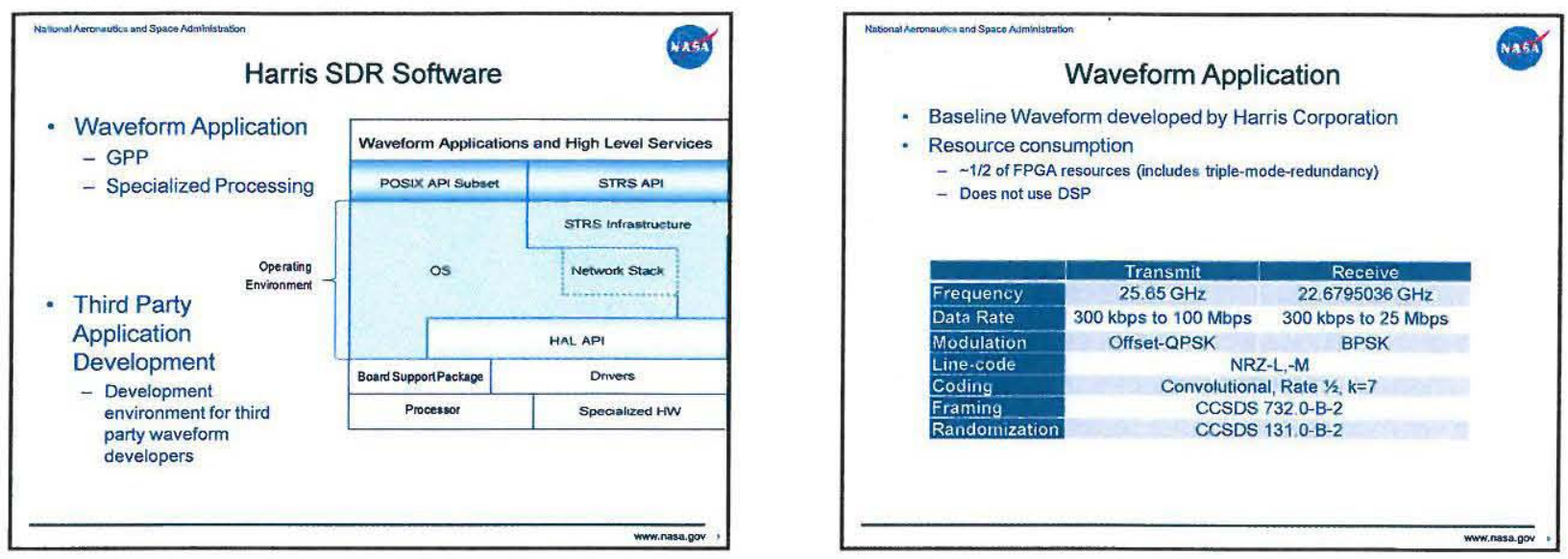

Testing
- Extensive testing performed at subsystem and integrated
system level
- TDRSS Compatibility
- Environmental: Vibration, Thermal, Thermal and Space Admintsuation
- Pre-flight system performance will be basis for on-orbit
evaluation
- Minimum Signal Level Tracking / Acquisition Threshold
- Acquisition Time, False Lock susceptibility
- Coded and Uncoded BER performance vs Eb/No
- Frequency Control, Frequency Tracking Range
- Transmitter Output Spectrum/Spectral Mask
- Carrier Suppression
Separation of Platform and Waveform Performance.
- Platform limited by hardware
- Waveform limited by implementation
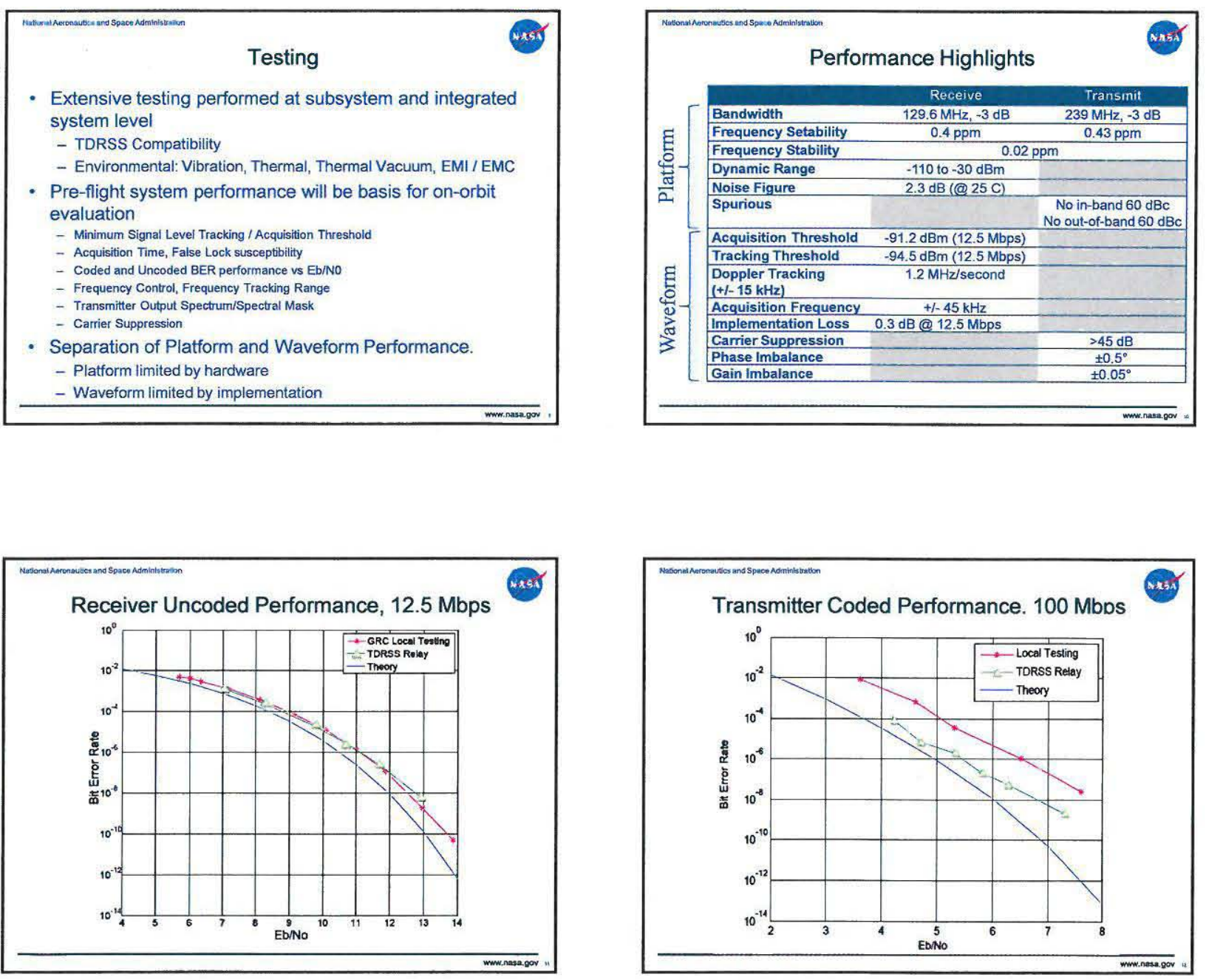


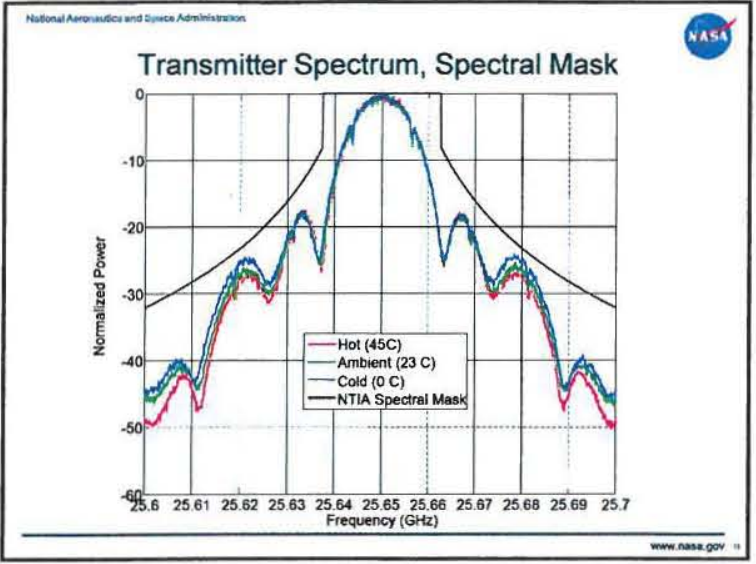

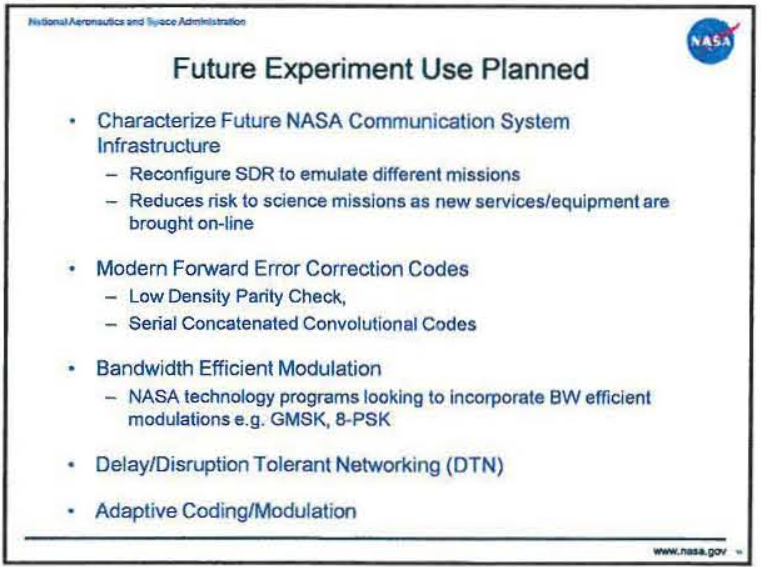

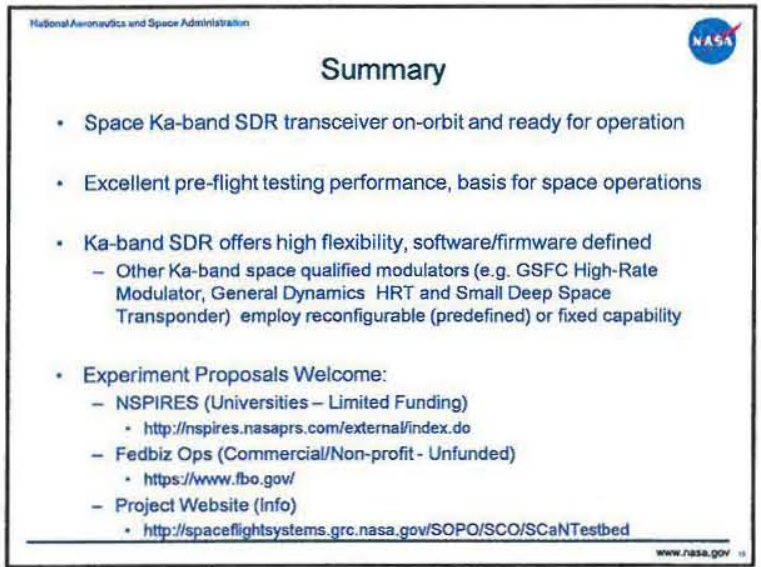




\section{Pre-flight Testing and Performance of a Ka-band Software Defined Radio}

Joseph Downey, Richard Reinhart, Thomas Kacpura

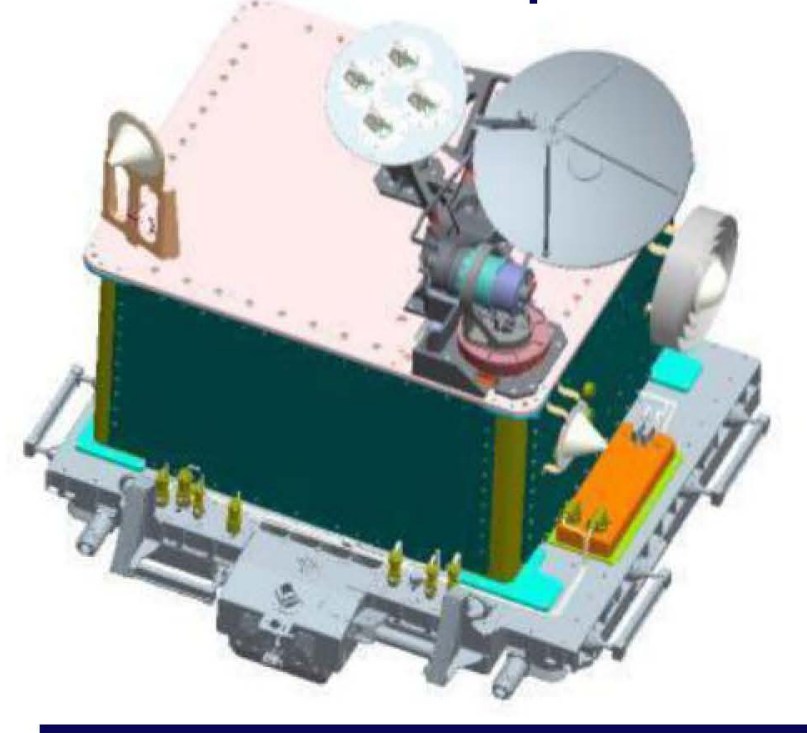
NASA Glenn Research Center Cleveland, Ohio 


\section{Outline}

- Background

- Ka-band SDR

- Testing

- Performance Results

- Future Work 


\section{Background}

- NASA is studying the development, testing, and operation of software defined radios (SDRs) for the space environment

- NASA has built a reconfigurable testbed comprised of SDRs for the space environment

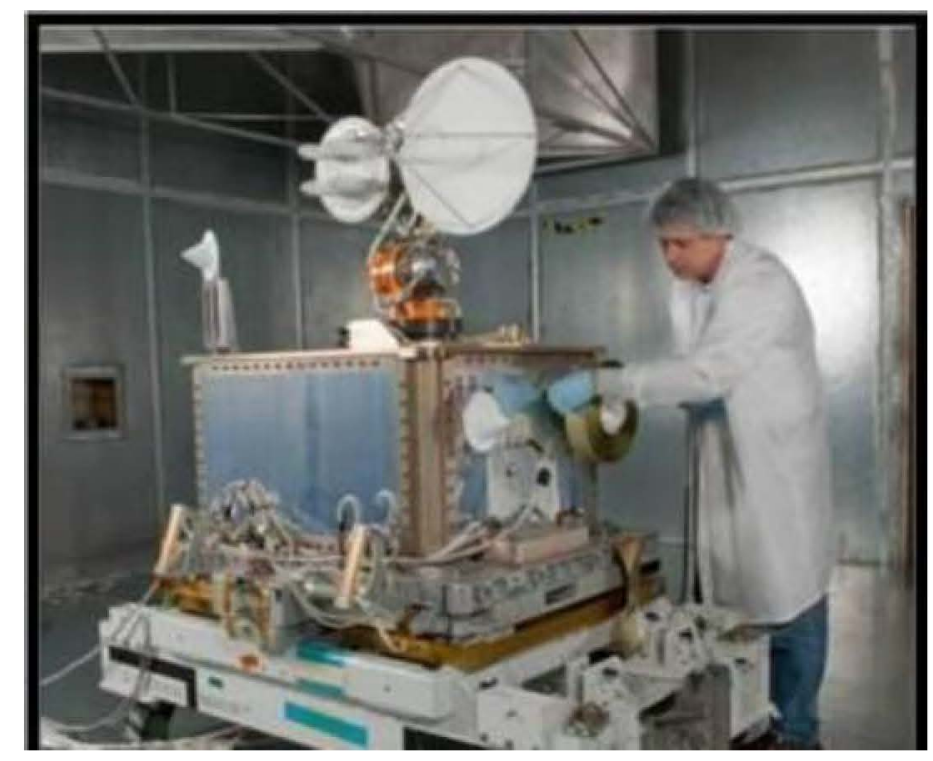

- SCaN Testbed

- 3 SDRs

- Space Telecommunications Radio System (STRS)compliant

- L-band, S-band, Ka-band

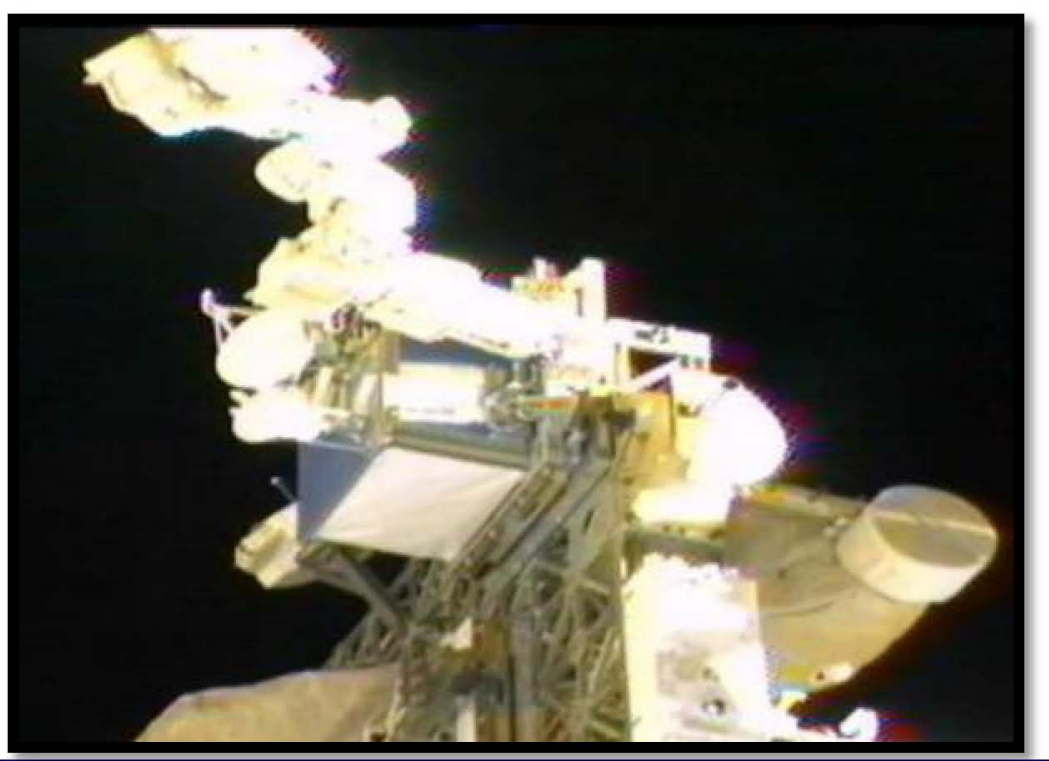




\section{SCaN Testbed Flight System Connections}

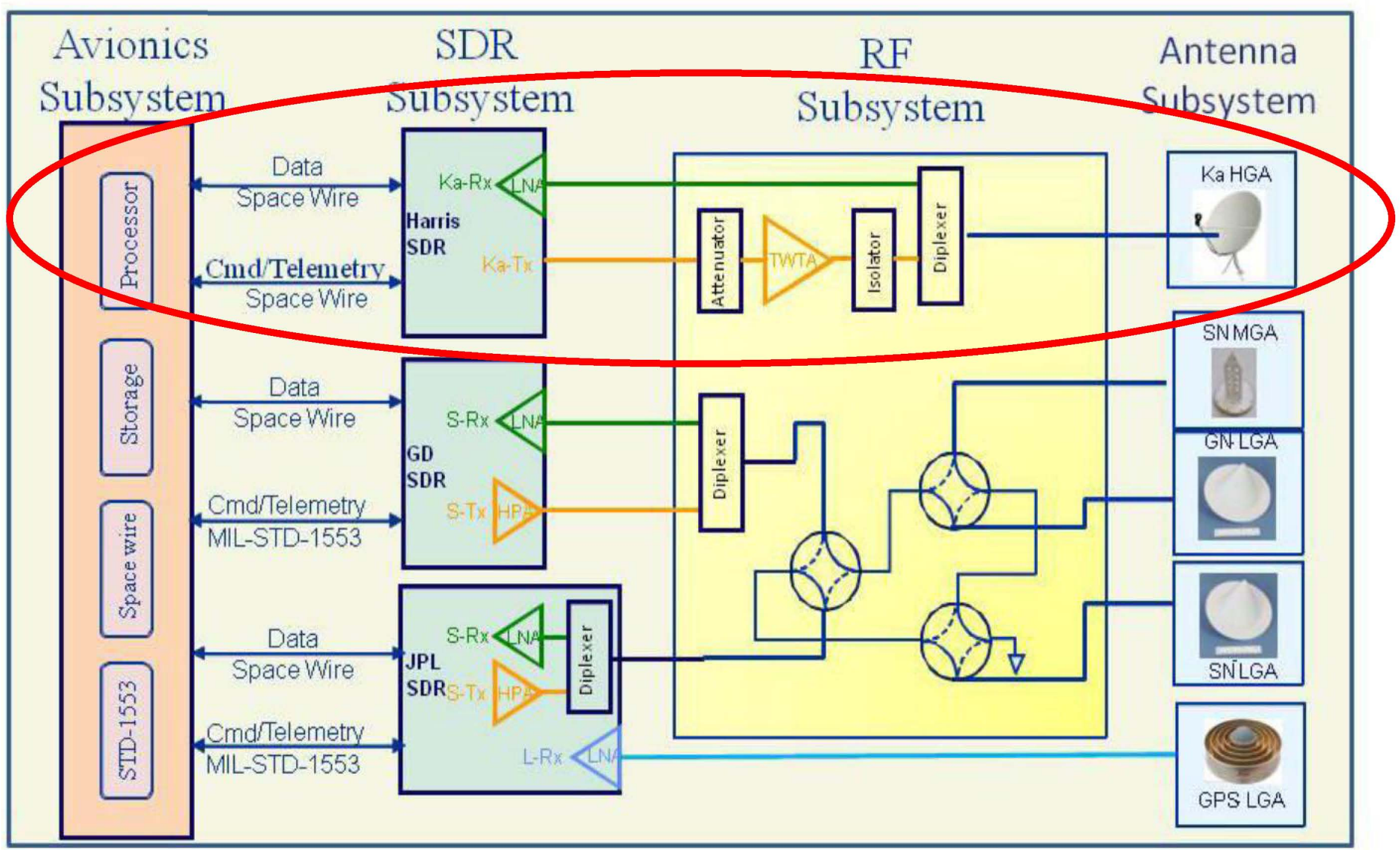




\section{Harris Corporation Ka-band SDR}

- Reconfigurable / Reprogrammable Signal Processing

- Field Programmable Gate Arrays (FPGAs)

- Digital Signal Processor (DSP)

- Single Board Computer, PowerPC

- STRS-compliant Operating Environment

- Manages waveform applications

- Command / Telemetry

- Tunable RF front-end, designed for the TDRSS* Kaband Service

- Receive: $22.515-23.115 \mathrm{GHz}$

- $50 \mathrm{MHz}$ bandwidth

- Transmit: 25.65 - 26.16 GHz

- $225 \mathrm{MHz}$ bandwidth

*TDRSS: Tracking and Data Relay Satellite System

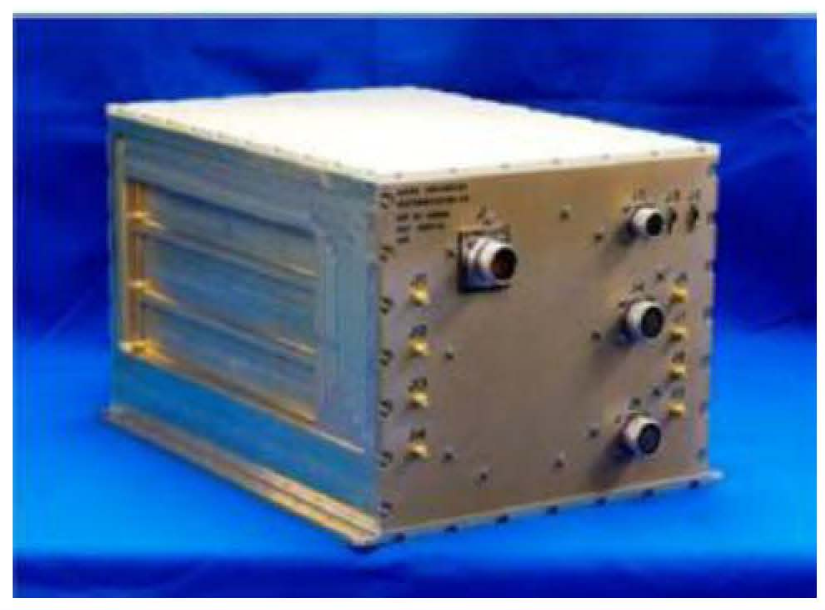




\section{Harris SDR Hardware}

- Features

- Modular architecture

- Mixture of commercial and custom cards

- 6U Compact-PCI backplane

- External S-band to Ka-band frequency converter

- Modem Processor

- Virtex IV FPGAs, DSP

- Management ASIC

- Scrubbing

- Configuration

- Internal SpaceWire Router

Size: $16 "$ x 10" x 8"

Weight: $19.2 \mathrm{~kg}$

Power: $100 \mathrm{~W}$ 


\section{Harris SDR Software}

- Waveform Application

- GPP

- Specialized Processing

- Third Party Application Development

- Development environment for third party waveform

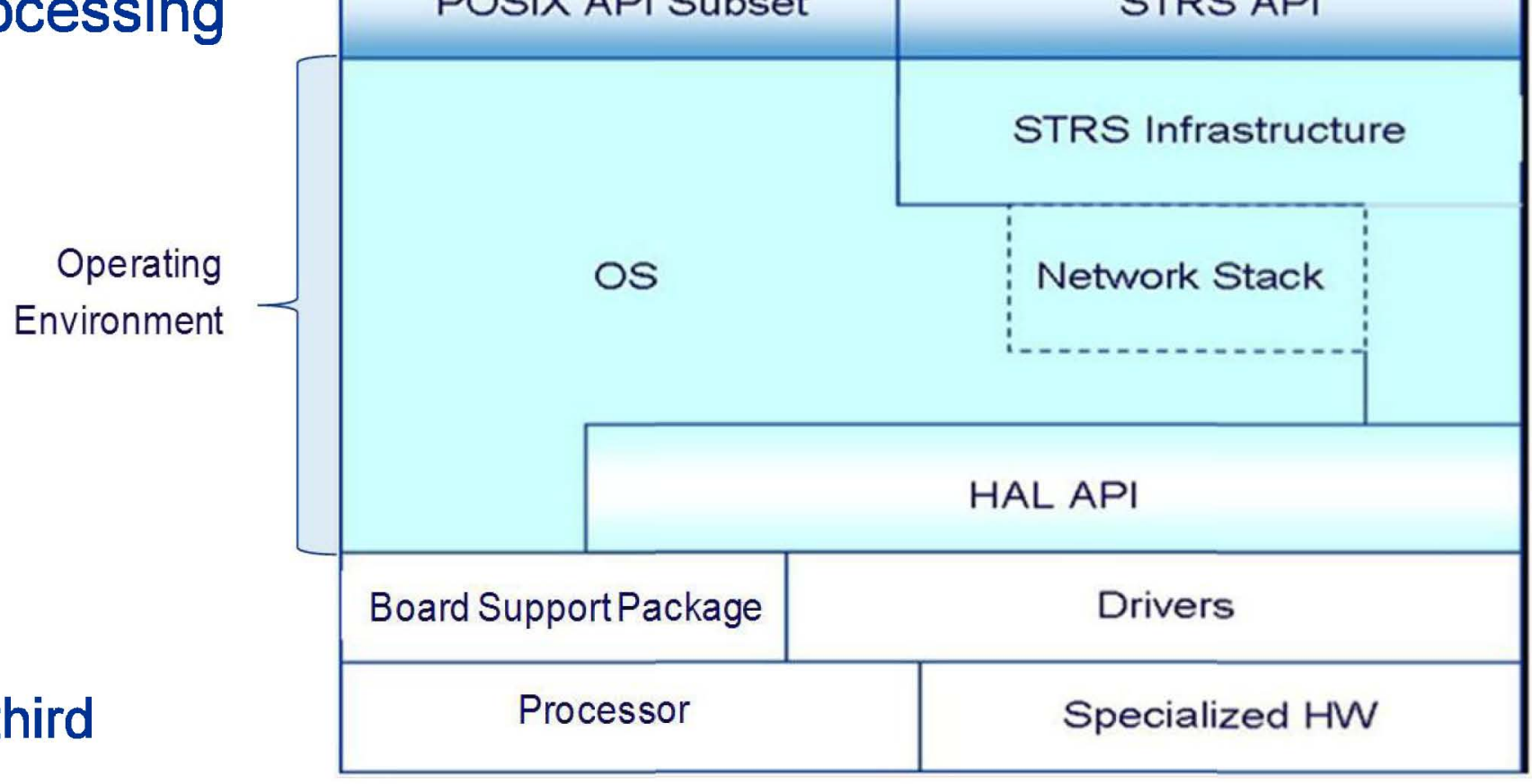
developers 


\section{Waveform Application}

\begin{tabular}{|c|c|c|}
\hline & & Receive \\
\hline Frequency & $25.65 \mathrm{GHz}$ & $22.6795036 \mathrm{GHz}$ \\
\hline Data Rate & Jps to $100 \wedge$ & $00 \mathrm{kbps}$ to $25 \mathrm{Mbps}$ \\
\hline Modulation & Iffset-QPSK & \\
\hline Line-code & & \\
\hline Coding & Convolu & Rate $1 / 2, k=7$ \\
\hline Framing & & \\
\hline Randomization & & \\
\hline
\end{tabular}




\section{Testing}

- Extensive testing performed at subsystem and integrated system level

- TDRSS Compatibility

- Environmental: Vibration, Thermal, Thermal Vacuum, EMI / EMC

- Pre-flight system performance will be basis for on-orbit evaluation

- Minimum Signal Level Tracking / Acquisition Threshold

- Acquisition Time, False Lock susceptibility

- Coded and Uncoded BER performance vs Eb/NO

- Frequency Control, Frequency Tracking Range

- Transmitter Output Spectrum/Spectral Mask

- Carrier Suppression

- Separation of Platform and Waveform Performance.

- Platform limited by hardware

- Waveform limited by implementation 


\section{Performance Highlights}

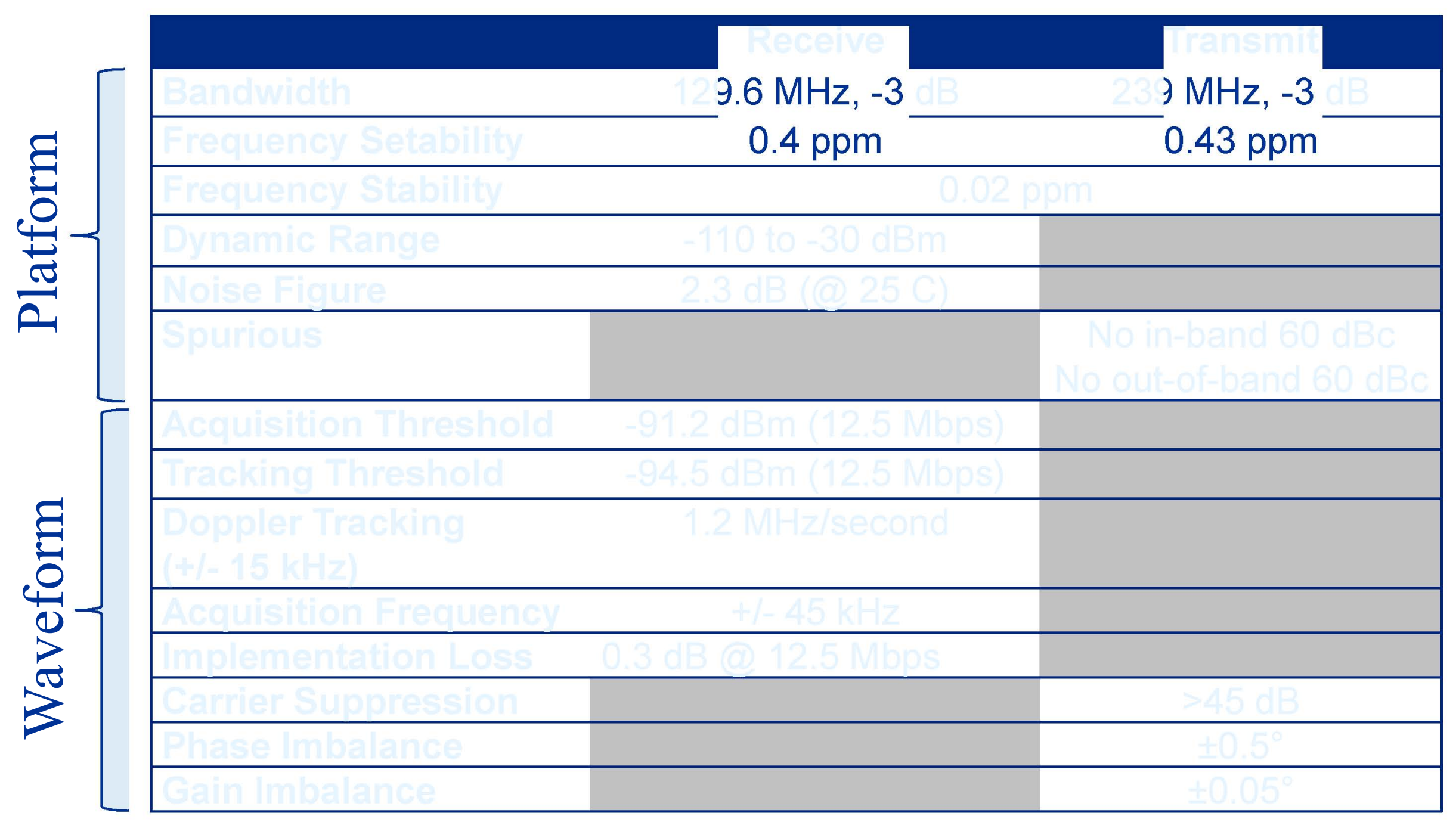




\section{Receiver Uncoded Performance, 12.5 Mbps}

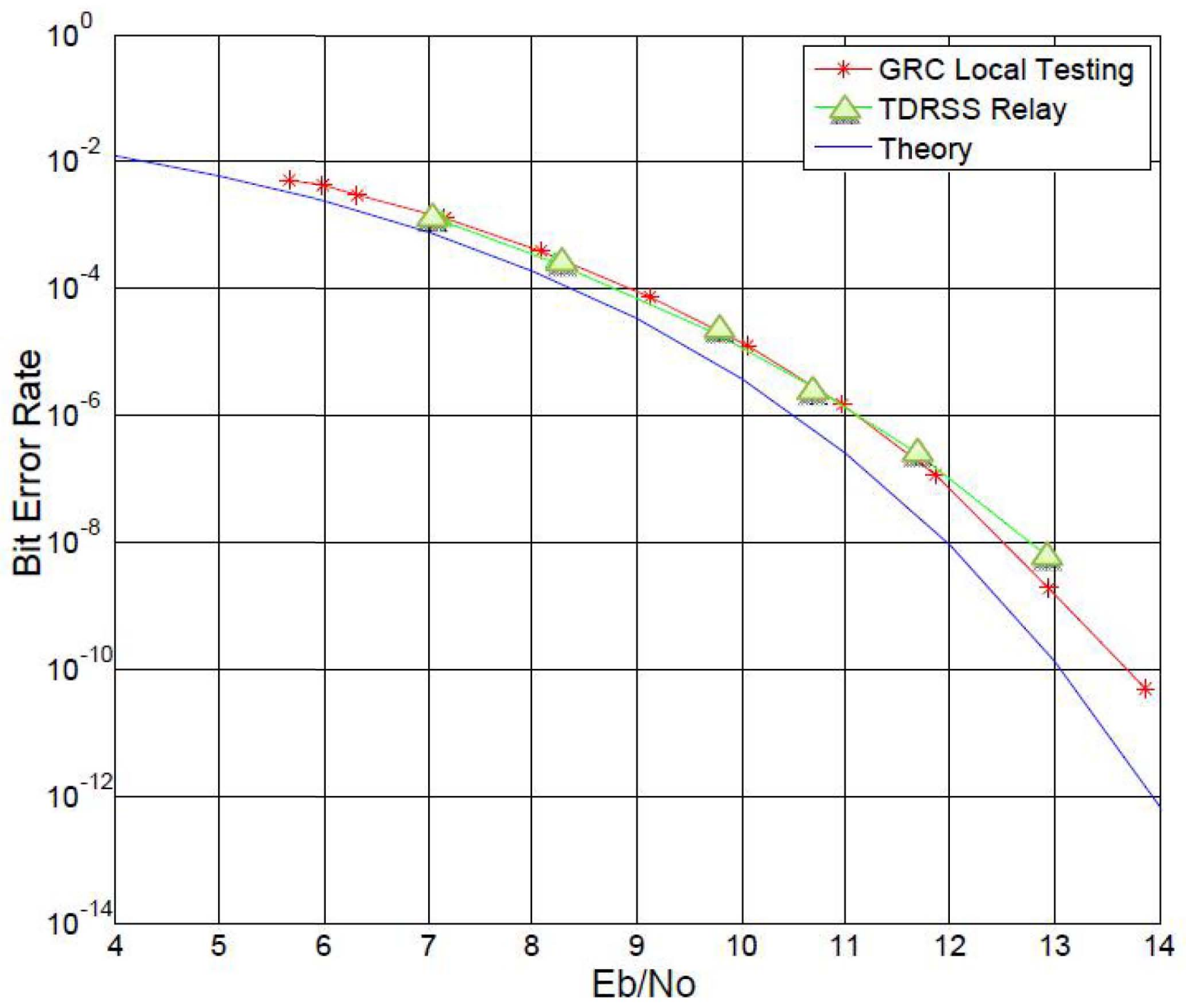




\section{Transmitter Coded Performance. 100 Mbos}

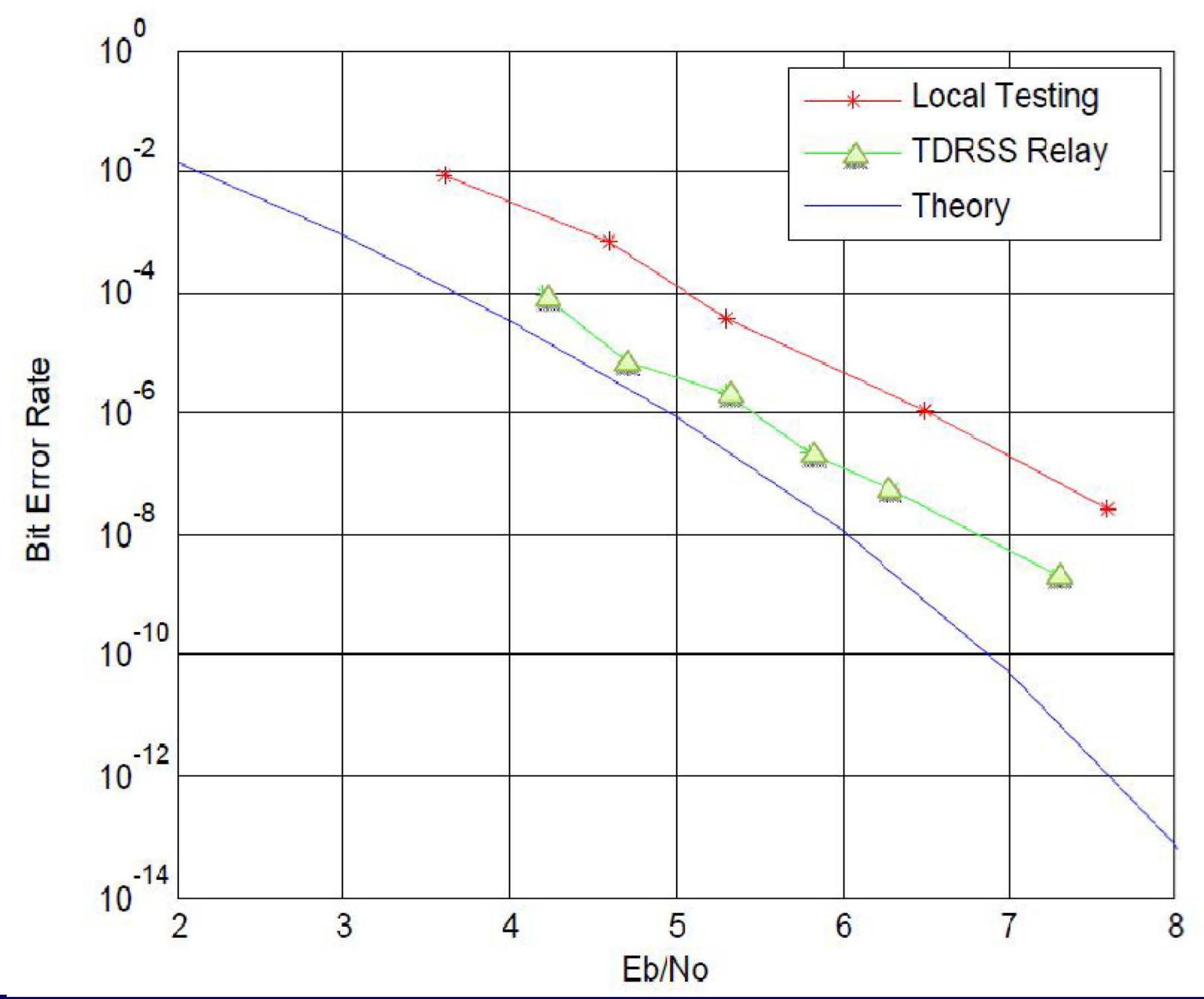




\section{Transmitter Spectrum, Spectral Mask}

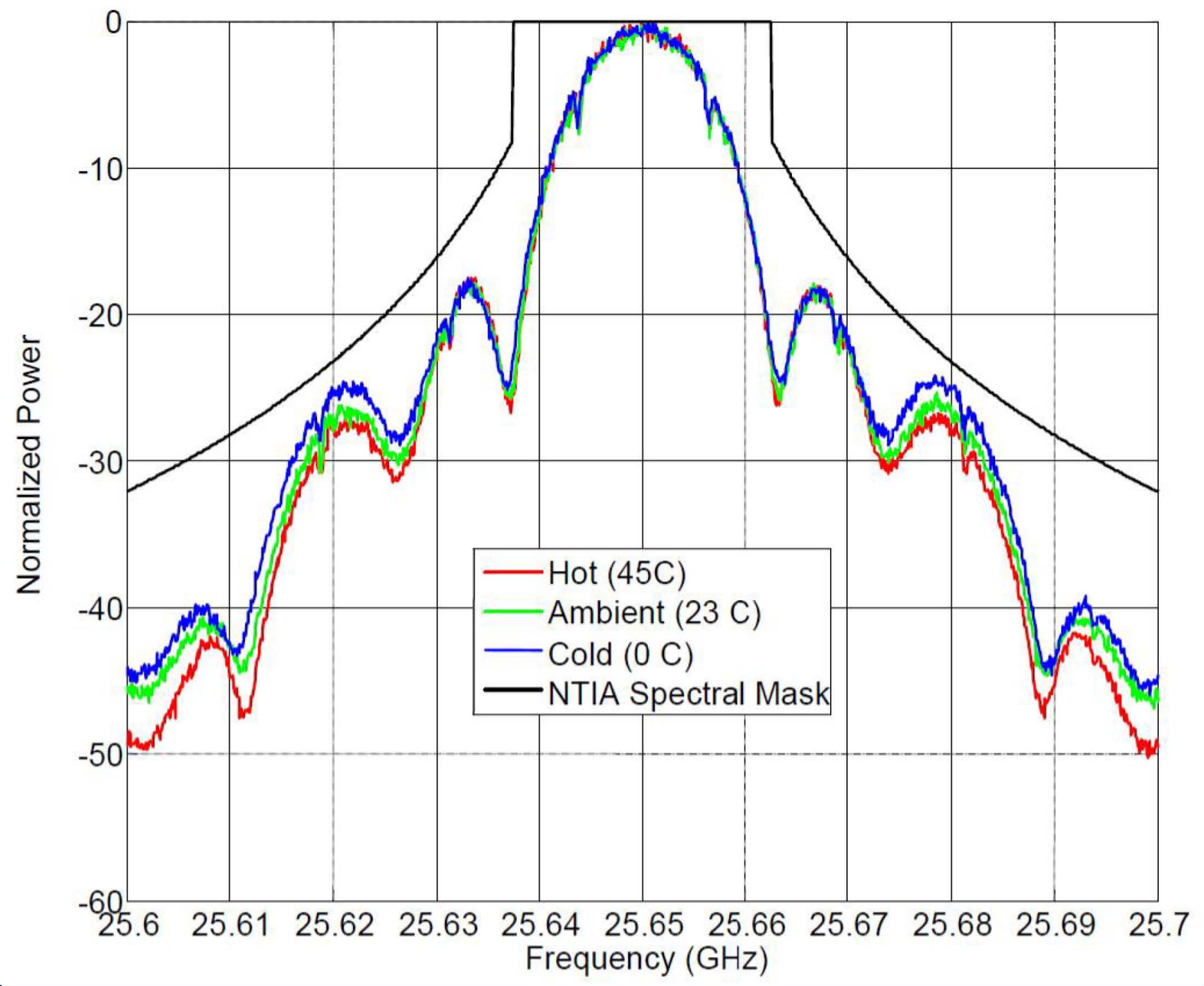




\section{Future Experiment Use Planned}

- Characterize Future NASA Communication System Infrastructure

- Reconfigure SDR to emulate different missions

- Reduces risk to science missions as new services/equipment are brought on-line

- Modern Forward Error Correction Codes

- Low Density Parity Check,

- Serial Concatenated Convolutional Codes

- Bandwidth Efficient Modulation

- NASA technology programs looking to incorporate BW efficient modulations e.g. GMSK, 8-PSK

- Delay/Disruption Tolerant Networking (DTN)

- Adaptive Coding/Modulation 


\section{Summary}

- Space Ka-band SDR transceiver on-orbit and ready for operation

- Excellent pre-flight testing performance, basis for space operations

- Ka-band SDR offers high flexibility, software/firmware defined

- Other Ka-band space qualified modulators (e.g. GSFC High-Rate Modulator, General Dynamics HRT and Small Deep Space Transponder) employ reconfigurable (predefined) or fixed capability

- Experiment Proposals Welcome:

- NSPIRES (Universities - Limited Funding)

- http://nspires.nasaprs.com/external/index.do

- Fedbiz Ops (Commercial/Non-profit - Unfunded)

- https://www.fbo.gov/

- Project Website (Info)

- http://spaceflightsystems.grc.nasa.gov/SOPO/SCO/SCaNTestbed 